\title{
Sustainable operation of geothermal power plants: why economics matters
}

\author{
Fynn V. Hackstein ${ }^{1}$ and Reinhard Madlener ${ }^{2,3^{*}}$ (])
}

\section{*Correspondence:}

RMadlener@eonerc.rwth-

aachen.de

${ }^{2}$ Institute for Future

Energy Consumer Needs

and Behavior (FCN), School

of Business and Economics

/ E.ON Energy Research

Center, RWTH Aachen

University, Mathieustrasse 10,

52074 Aachen, Germany

Full list of author information

is available at the end of the article

\begin{abstract}
This paper, based on a novel hybrid techno-economic model for geothermal power plants with endogenized plant lifetime, investigates the economic feasibility of a sustainable exploitation of geothermal resources for electricity generation. To this end, standard terminology and classifications from the literature are reviewed, such as "sustainability", "sustainable operation", "renewability", "recovery", "recharge", and "regeneration". An illustrative conventional, convective high-enthalpy hydrothermal system is contrasted with an enhanced, conductive low-enthalpy petrothermal system. Furthermore, different (mostly geophysical) sustainable operation criteria for the use of geothermal energy are derived from the literature. The conditions for complying with these criteria are compared with the economic criteria of cost minimization (levelized cost of electricity, LCOE) and profit maximization (net present value, NPV), respectively, revealing differences that vary in intensity, particularly depending on the type of reservoir and their respective properties. For the two case studies, LCOE of $2.9 €-\mathrm{ct} / \mathrm{kWh}$ and $16.9 €-\mathrm{ct} / \mathrm{kWh}$ are found, which are further scrutinized by a detailed sensitivity analysis. The hydrothermal system, in contrast to the petrothermal system investigated, is found to be able to meet several of the sustainability criteria examined (extraction equals recharge, operating lifetime of 100 to 300 years), whereas economically optimal operation leads to excessive overexploitation in both cases, showing a distinct trade-off between profit maximization and sustainable operation that has not been discussed in the literature so far.
\end{abstract}

Keywords: Sustainability, Geothermal recharge, Power generation, Convection, Conduction, Enhanced geothermal system, Hydrothermal and petrothermal geothermal systems, Economics, Sensitivity analysis

JEL Classification: D25, Q25, Q32, Q42, Q57, R32

\section{Introduction}

To meet the challenges of climate change, renewable energy sources will have to replace fossil fuels at a massive scale well before the end of this century (Bauer 2014a: 27). Especially the vast and ubiquitous energy stored in the earth's interior offers an immense potential to which more attention should be paid (Mongillo et al. 2010: 9). The heat and power generation from geothermal sources is continuously available and therefore base-load capable, which is an important advantage over most other renewable energy sources (Zhang et al. 2014: 788). Moreover, it can be found "practically

(c) The Author(s) 2021. This article is licensed under a Creative Commons Attribution 4.0 International License, which permits use, sharing, adaptation, distribution and reproduction in any medium or format, as long as you give appropriate credit to the original author(s) and the source, provide a link to the Creative Commons licence, and indicate if changes were made. The images or other third party material in this article are included in the article's Creative Commons licence, unless indicated otherwise in a credit line to the material. If material is not included in the article's Creative Commons licence and your intended use is not permitted by statutory regulation or exceeds the permitted use, you will need to obtain permission directly from the copyright holder. To view a copy of this licence, visit http://creativeco mmons.org/licenses/by/4.0/. 
everywhere" (Barbier 2002: 56f) because the heat stored in the bedrock is supplied both by radioactive decay within the rock and by the heat flow from the earth's interior all around the world (Bauer 2014b: 7). Even if the technical potential ${ }^{1}$ is only a fraction of the energy stored underground, it could still cover human energy needs for centuries (Tester et al. 2006: 12; Paschen et al. 2003: 5). Geothermal resources have been defined as "the energy that could reasonably be extracted at cost competitive with other forms of energy at some specified future time" (Muffler and Cataldi 1978: 53). Up to now, however, economical use only exists for a few places with particularly favorable site conditions (Grant and Garg 2012: 1). As a result, with $16 \mathrm{GW}_{\mathrm{e}}$ of installed capacity in 2020 (Hutter 2020: 2), geothermal energy represents only a tiny share of world total electricity generation.

In the future, so-called enhanced geothermal systems (EGS) could also enable to develop unconventional reservoirs which do not by nature provide all optimal conditions required for the recovery of geothermal energy (Tester et al. 2006: 1). Some 90\% of the total accessible geothermal energy is present in the form of hot dry rock (HDR) (Jiang et al. 2014: 300), which is characterized by low permeability and the absence of water (Stober and Bucher 2014: 53). Using EGS technology these HDRs could be used to create artificially fractured reservoirs at the desired volume, with appropriate temperature, and at an accessible depth (Barbier 2002: 55). "This will provide almost unlimited energy, since almost any geological site [...] could be considered as a reservoir" (Chamorro et al. 2012: 12). Due to this, EGS, as an emerging HDR heat utilization technology, has attracted broad attention in many countries around the world (Dalmais et al. 2019; Jiang et al. 2014: 300; Ziagos et al. 2013: 1). At the end of 2019, there were 130 operating power plants in Europe, with a total generation capacity of $3.3 \mathrm{GW}_{\mathrm{e}}$, an additional 36 projects under development, and another 124 projects in the planning phase. This means that the number of operating plants could double within the next 5 to 8 years (EGEC 2020: 9).

Geothermal energy is often considered both a sustainable and a renewable energy source, but these terminologies must be handled with caution, especially with regard to conductive systems. While the former describes how the resource is utilized, the latter describes a natural property of the resource (Stefansson 2000: 883; Axelsson et al. 2010: 3). There are different and controversial definitions in the literature, so that a clarification and proper use of these terms is an absolute necessity in order to avoid confusion both in research and the political discussion.

Obviously, some technological barriers still exist that prevent the massive use of geothermal energy. In the case of deep geothermal energy use, in addition to the need for drilling several kilometers into crystalline basement rock formations, reservoir stimulation creates additional challenges and obstacles. It has not yet reached the level that a desired network of fractures can be achieved without severe efforts (Chen and Jiang 2015: 41). Consequently, well productivity remains another great technological challenge for the commercialization of EGS (Jelacic et al. 2008: 6). However, given the developments in power generation, such as the rapid rise in photovoltaics over the last two

\footnotetext{
${ }_{1}^{1}$ The technical potential for geothermal power generation describes the share of the theoretical potential that can be "technically exploited" taking into account current technical possibilities (Paschen et al. 2003: 23; Rybach 2010: 2; EPA 2007: 2-4).
} 
decades, which 20 years ago was surpassed by a factor of 100 by geothermal energy in terms of electricity production (Fridleifsson 2001: 308), it is important to consider further possible technical breakthroughs in other segments as well. Given the right circumstances, such as a stable policy framework, proper insurance schemes, sound research and development and demonstration (RD\&D) policies as well as carbon pricing and the abandonment of supporting fossil fuels, the use of geothermal energy could scale up very rapidly (EGEC 2020: 15).

The future of geothermal energy will strongly depend on the extent that geothermal power plant deployment can be accelerated. Other sources of renewable energy are developing rapidly, whereas geothermal power growth over the last 5 years has been limited to a mere $3.65 \mathrm{GW}_{\mathrm{e}}$ and only slightly offsets the linear growth trend observed since 2010 (Hutter 2020: 1). However, if the state of the art is about to reach a level at which commercial use of geothermal energy would be feasible at any given place, it is of interest to know in advance what the usage of these resources and the resulting effects could look like. Therefore, the focus of this study is not exclusively on natural systems, but also EGS.

Economics and sustainable operation of geothermal resources are two topics that are usually considered as two separate issues in the literature. This research aims to establish a connection between the two fields via a hybrid techno-economic optimization model that treats extraction rates as endogenous, thus enabling the joint evaluation of geothermal resources in both monetary terms (economic viability, profit maximization) and with regard to optimal lifetime (sustainability of resource use). To set up the model, a comprehensive review of current literature in the field of sustainability and economics regarding geothermal power generation was carried out. On this basis, several cost functions were derived, which ultimately can all be displayed as a function of the extraction rate, which in return determines the expected reservoir lifetime. In addition to this, the model also includes geological properties that reflect the regeneration capacity of the reservoir. Although the model is partly built on some broader generalizations, its integrated and interdisciplinary formulation nevertheless provides a strong and general foundation for the evaluation of deep geothermal energy systems, and is suitable for the implementation of more sophisticated submodels.

The remainder of this paper is organized as follows. In the following section, all necessary background information is provided. In addition to the geological and technical aspects, a definition and clarification of the terms "sustainable" and "renewable" is provided for the purpose of this study but also further use. On that basis, production modes and their impacts on different reservoir structures are discussed, which serves as the foundation for the discussion of all parameters needed for the optimization model proposed. Next, the two exemplary cases considered-a convective hydrothermal as well as a conductive petrothermal system-are described in detail. Then, the hybrid model is applied and a sensitivity analysis with variations of key parameters undertaken to check the robustness of the results, and to discuss the implications on the sustainability of operation. It allows to better understand the differences between sustainable operation with and without accounting for profitability considerations, and the two exemplary cases investigated. This way, we are able to show that the question of sustainable production of a geothermal reservoir ultimately depends not only on the specific geological conditions, but also on the way resource use is affected by market-based conditions. A 
key difference of this work compared to other analysis (e.g., Frank et al 2012: 3; IRENA 2017: 14; Knaut et al 2012: 25) or publicly available tools, such as the geothermal electricity technology evaluation model-GETEM (EERE 2016), is that the reservoir lifetime is not considered as an exogenously determined, fixed value but treated as endogenous, which is what makes the discussion about (non-)sustainable operation possible in the first place. This is an important and original contribution to the existing literature.

\section{Theoretical background}

\section{Reservoir characteristics}

The following classification of geothermal reservoirs is based on the type of energy inflow to the system, namely conduction and convection. Usually a subdivision of geothermal systems in dependence of the reservoir's enthalpy is common (e.g., Bodvarsson 1964; Muffler 1979; Haenel et al. 1988; Benderitter and Cormy 1990; Sanyal 2005). However, temperature is not necessarily linked to the heat transport mechanism, which is meant to play an important role in the context of sustainable operation.

Convection-based reservoirs: Convection-based systems comprise the vast majority of operating geothermal power plants worldwide. Due to their presence and the many decades of operation they are also referred to as conventional or natural systems (Friedleifsson et al. 2008: 68; Williams 2010: 1). They are either controlled by an igneous activity in volcanic areas, faults in extensional terrains, or a combination of both, such as intrusive bodies at fault zones (Moeck 2014: 871). Due to strong heat anomalies and the convective setting, the natural energy flow to such a system can be very high (O'Sullivan et al. 2010: 314). We hereafter refer to the energy flow towards the system as recharge.

Classically, convective geothermal reservoirs are of a hydrothermal nature, but also the recharge of unconventional EGS could be based on convection, as for example with favorable conditions like in the Upper Rhine Graben, where hydraulic-convective heat and fluid re-supply from the far field can be effective due to large-scale permeable faults (Vidal and Genter 2018: 68).

Conduction-based reservoirs: Geothermal systems in passive plate tectonic settings are usually conduction-based due to the absence of asthenospheric anomalies as well as faults in the crust. A distinction can be made between reservoirs in sedimentary rock and crystalline rock. The former includes hydrothermal systems, meaning deep aquifers that have been heated by a near normal heat flow (Moeck 2014: 874), while the latter is referred to as a petrothermal system, but more commonly known as HDR. The energy recharge of a conduction-based reservoir is quite limited compared to that in a convective setting. It is a relatively slow process where a time constant of the order of hundreds of years is needed to characterize the process, whereas time constants in the range of days or months are suitable to describe the process of convection (Stefansson 2000: 884-885).

\section{Sustainability and renewability}

Sustainability is a very comprehensive topic. This work considers only the temporal component, as sustainability is first and foremost a question of the temporally resolved consumption of an existing resource in connection with its regeneration rate. Neither social aspects nor environmental impacts such as seismicity, changes in the landscape or effects on organisms are considered. 
Geothermal energy is usually referred to as a renewable source of energy and is also considered as environmentally benign. Both attributes are indeed applicable, but within certain limits, which must be addressed in a fully objective manner. Rybach (2003: 464) points out that "[a]ny attempts at disguising or even concealing production decline or a possible impact on the environment could bring discredit upon an entire industry, spreading mistrust amongst the authorities as well as the general public." We therefore take an approach to clarify where the boundaries of sustainable operation lie and how economic optimization can create a trade-off versus sustainability of operation. When immersing in the subject, we have come across some inconsistencies and ambiguities which have been denounced by other authors in the field as well, e.g., Hähnlein (2013), Stefansson (2000), Axelsson et al. (2010), Steingrimmson (2006) and Rybach and Mongillo (2006). In our opinion, this is mainly due to the fact that extraction patterns are not put in relation to the renewability of a reservoir, which in turn is largely determined by the reservoir type (either being convective or conductive). Further, the terms renewable and sustainable are often confused (Axelsson and Stefánsson 2003: 41). Based on the work of Stefansson (2000), which is generally supported by many other authors in this field, we want to contribute to a better understanding of these terminologies. In order for a geothermal resource to be sustainable it must be renewable. While the latter describes a property of the energy resource, the former describes how a resource is utilized. Imagine a developed reservoir. It is composed of three main variables: an initial stock of recoverable heat $S$, a natural energy recharge rate $R e$ to this stock, and an extraction rate of energy $E$. True sustainability is achieved when the extraction is equal to or less than the natural inflow of energy (Barbier 2002: 37; Rybach 2003: 464-465), $E \leq R e$, with the extraction rate $E$ being subject to the operator's control. On the one hand, this entails that the operator determines whether or not a reservoir under production can be considered as sustainable while, on the other hand, this means that the level of extraction rate meeting the sustainability criterion depends on the natural recharge. This leads to the concept of renewability, describing the regeneration properties of the geothermal reservoir. Axelsson et al. (2010) state that geothermal resources are normally classified as renewable energy sources, which is consistent with the classification of international agencies (Stefansson 2000: 883), because they are maintained by a continuous energy current. However, they also point out that such a classification may be an oversimplification. In line with what we have established so far, they highlight that the stored energy is under certain circumstances renewed quite slowly, especially the part that is renewed by heat conduction, so that geothermal energy is not necessarily a renewable energy source on a human time scale. This again reflects that the degree of renewability determines whether a reservoir can be considered to be sustainable or not.

After discussing what 'true' sustainable production means in terms of the extraction of geothermal resources, we will provide a definition of production in a sustainable manner adopted in the field, since for economic reasons, true sustainable operation is only possible in very few cases with a corresponding high energy recharge. Production in a sustainable manner has been described by means that "[...] the production system applied is able to sustain the production level over long times" (Rybach and Mongillo 2006: 1083). In Iceland, a reference period of 100 to 300 years has been proposed (Axelsson et al. 2005), while in New Zealand production for a period longer than 100 years is considered 


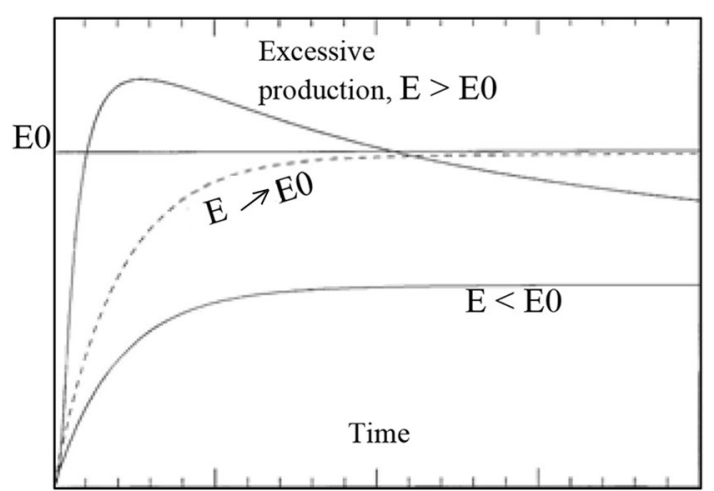

Fig. 1 Schematic illustration of the difference between sustainable and excessive production. (Source Steingrimsson 2006: 4)

Table 1 Level of sustainability in dependence of extraction/recharge ratio

\begin{tabular}{lll}
\hline Level of sustainability & Extraction/recharge ratio & Operation time (relative values) \\
\hline Truly sustainable & $E \leq R e$ & Infinite \\
Sustainable manner & $E \leq E 0$ with $E>R e$ & 100 to 300 years \\
Unsustainable & $E>E 0$ with $E>>R e$ & Few decades ( $<100$ years) \\
\hline
\end{tabular}

as sustainable (Bromley et al. 2006). Hähnlein et al. (2013: 915) state that " $t]$ his technical interpretation of sustainability is oriented at the extractable energy of the natural system and is suitable especially for deep production systems" and seems more suitable for the purposes compared to an infinite operation time. However, how long the maximum lifetime of a geothermal reservoir can be extended without violating its economic viability depends largely on its size, whereas a predefined fixed value such as 100 years may be highly inappropriate. Time frames for geothermal power plants in economic analysis are generally in the order of only some 30 years. This is not only due to concessions granted by the mining authority, but also to factors such as the technical lifetime of plant components and the limitation of production to an economically relevant time frame.

This means that in contrast to true sustainable operation, which requires $E \leq R e$, this technical interpretation allows extraction rates $E>R e$, but in such a way that the production is feasible for very long periods of time. Axelsson et al. (2010:3) paraphrase the extraction rate that meets this criterion as follows: "For each geothermal system, and for each mode of production, there exists a certain level of maximum energy production, EO, below which it will be possible to maintain constant energy production from the system for a very long time [...]. If the production rate is greater than EO it cannot be maintained for this length of time. Geothermal energy production below, or equal to EO, is termed sustainable production while production greater than EO is termed excessive production." (see Fig. 1). Note that this definition neither considers further environmental issues nor economic aspects (i.e., such a production level may not be feasible under certain circumstances) but applies to the extractable energy and depends on the nature of the system. Table 1 gives an overview of the deduced criteria of sustainable operation relevant to this work. 


\section{Endogeneity of reservoir lifetime}

For most geothermal reservoirs an excessive production scheme is pursued (O'Sullivan et al. 2010: 314), as production rates in a (geophysically) sustainable manner are very limited and often found to be uneconomical (Rybach 2003: 465). The reasons for the economic incentives lie, among others, in the quick payback of investments, as well as the time preference with regard to future profits (Rybach and Mongillo 2006). For high extraction rates the energy yield will be high at the beginning (and with it the economic benefits), but the energy delivery will decrease over time, in a way which may cause the breakdown of a commercially viable operation. The drawbacks of an excessive production scheme that overexploits the resource beyond its regenerative capacity come in the form of a stronger production decline than otherwise and a shorter lifetime of the reserve (and thus plant), i.e. the part of the resource that can economically be extracted, and possibly resulting in a lower amount of electricity generated overall.

For the economically optimal exploitation of a finite resource, usually the Hotelling rule (Hotelling 1931) is applied, which represents the trade-off between exploiting some reserve of interest for gaining revenues at current prices immediately and leaving it in the ground for later use when prices expectedly have increased due to the finiteness of the resource (so-called "scarcity rent"). For two reasons, however, Hotelling's classical model is not directly applicable to geothermal energy: first, the product sold (in our analysis) is electricity, therefore competing with all other ways of generating electricity, some of which might be cheaper also in the long run (so-called "backstop technologies"). Secondly, the energy stored in the earth is also inexhaustible on a human timescale, and geothermal energy usage describes only a local degradation of heat, which can be extracted in less favorable locations as technology progresses and costs can be brought down further. The Hotelling rule states that the owner of a finite resource is only willing to sell that amount immediately if it does not allow to gain more profit if sold later, assuming an increase in price (due to the finiteness of the resource) in lockstep with the market interest rate. Reversing the basic logic behind the Hotelling model provides an economic explanation for non-sustainable production also of resources that are non-finite in principle, but at the same time exhaustible. Since the Hotelling model was designed for the optimal exploitation of finite resources, i.e., such without recovery and regeneration properties, some modifications are required that are described in the following section.

\section{Model formulation}

The aim of our research is to develop a comprehensive hybrid techno-economic optimization model for analyzing the optimal temporal exploitation of a specific geothermal reservoir. This allows us to demonstrate the violation of sustainable operation due to economic considerations and, by performing a sensitivity analysis, also to identify those parameters that have the greatest impact on profitability and sustainability. The model consists of three components: (1) a geological sub-model, describing the natural properties of the resource; (2) a technical sub-model, addressing the respective technical constraints that arise; and (3) an economic sub-model, reflecting the economically rational (profit-maximizing) behavior of a power plant operator (Fig. 2). The parameters 
Table 2 Model parameters

\begin{tabular}{lll}
\hline Geophysical & Technological & Economic \\
\hline Heat in place & Extraction & CAPEX \\
Reservoir volume & Average well productivity & Surface investment \\
Porosity & Production decline & Subsurface investment \\
Temperature & Reservoir lifetime & Exploration \\
Recoverable heat & Reinjection & OPEX \\
Recovery factor & Electricity conversion & Operation \\
Recharge & Capacity factor & Maintenance \\
Convection/conduction & & Revenues \\
Radioactive decay & & Interest rate \\
Compensation from surroundings & & \\
\hline
\end{tabular}

CAPEX capital expenditures, OPEX operating expenditures

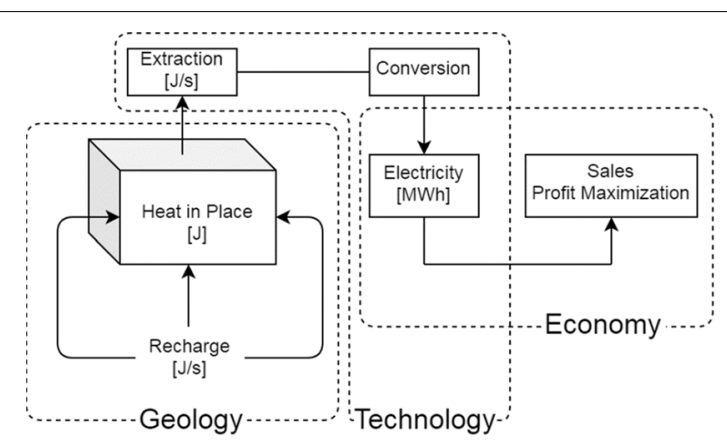

Fig. 2 Schematic model illustration

considered are grouped into three categories-geophysical, technological and economic ones (see Table 2) and discussed in the following.

\section{Geophysical parameters \\ Heat in place}

Starting point is the calculated heat content of the reservoir, generally known as "heat in place" (HIP). It corresponds to the amount of heat that can be obtained when the reservoir cools down to the temperature on the earth's surface. The calculation accounts for the specific heat capacity $c\left(\mathrm{~J} \mathrm{~kg}^{-1} \mathrm{~K}^{-1}\right)$, density $\rho\left(\mathrm{kg} \mathrm{m}^{-3}\right)$, volume $V\left(\mathrm{~m}^{3}\right)$, and temperature $T_{\mathrm{a}}\left({ }^{\circ} \mathrm{C}\right)$ of the reservoir or aquifer. The average temperature on the earth's surface $T_{\mathrm{S}}\left({ }^{\circ} \mathrm{C}\right)$ is used as a counterpart (Paschen et al. 2003: 23). Equation (1) governs the HIP, which in the following is referred to as a dynamic stock, $S_{0}$, of a given reservoir or aquifer (Gringarten 1978: 300):

$$
S_{0}=\rho_{\mathrm{a}} \cdot c_{\mathrm{a}} \cdot V \cdot\left(T_{\mathrm{a}}-T_{\mathrm{S}}\right)
$$

while Eq. (2) (Gringarten and Sauty 1975: 4957):

$$
\rho_{\mathrm{a}} \cdot c_{\mathrm{a}}=\Phi \cdot \rho_{\mathrm{f}} \cdot c_{\mathrm{f}}+(1-\Phi) \cdot \rho_{\mathrm{r}} \cdot c_{\mathrm{r}}
$$

considers the heat capacity of the aquifer via the porosity $\Phi(\%)$ and the different heat capacities of fluids and rocks. 


\section{Recovery factor}

Since not all of the heat stored in the reservoir is actually recoverable, we introduce the recovery factor $R(\%)$, which reflects the recoverable portion of the heat and is primarily dependent on reservoir structure, not temperature (Williams 2010: 1). Multiplication of the initial stock by the recovery factor gives the amount of heat that can be recovered, $S_{\mathrm{R}}(\mathrm{J})$.

$$
S_{\mathrm{R}}=S_{0} \cdot R \text {. }
$$

In order to address this value, we refer to values from the literature for various reservoirs. Recovery factors of natural geothermal systems generally lie between 5 and 20\% (Garg and Combs 2010; Williams 2010: 1) for EGS systems, the heat recovery factor is expected to be lower because of the difficulty in emulating naturally fractured systems (Grant and Garg 2012). Even though recovery factors in the range of $20-50 \%$ or even beyond have been derived from analytical numerical models under ideal conditions for EGS reservoirs (Sanyal and Butler 2005; Chen and Jiang 2015: 46; Tester et al. 2006), single-digit values seem to be more reasonable for non-homogeneous systems in real world applications (Kohl et al. 2008: 28; Grant and Garg 2012; Williams 2010: 6; Jelacic et al. 2008: 4). This extreme difference is due to the fact that these models assume that the fractures are uniform and closely spaced, thus neglecting preferential flow, which would result in increased cooling of the main heat exchange surfaces (Grant and Garg 2012). For the above reasons, we opt for an EGS recovery factor of $5 \%$ as suggested by various authors (e.g., Jelacic et al. 2008: 5; Williams 2010: 6). In addition, we take into account the thermal compensation of the surrounding rock. Chen and Jiang (2015) were able to model the effects caused by the heat difference between the rock matrix in the porous reservoir and the impermeable boundary rocks. They conclude that for a homogeneously fractured reservoir, depending on proper well layout, about $4-8 \%$ of the heat extracted by the outflow fluid has originated from the rock mass enclosing the reservoir. Since this value is expected to be significantly lower for a natural geothermal system, we have assumed a value of $1 \%$ (and 6\% for the EGS case, respectively).

\section{Recharge}

The recharge is composed of heat production due to radioactive decay $H_{\mathrm{R}}\left(\mathrm{W} \mathrm{m}{ }^{-3}\right)$ within the reservoir and heat flow from the earth's interior $H_{\mathrm{F}}\left(\mathrm{W} \mathrm{m} \mathrm{m}^{-2}\right)$, and may be convective or conductive. With $V_{\mathrm{r}}\left(\mathrm{m}^{3}\right)$ being the rock volume and $A\left(\mathrm{~m}^{2}\right)$ the surface area of the reservoir, we can formulate the total recharge $(\mathrm{J})$ to the reservoir over its lifetime as:

$$
\int_{0}^{\Delta t} \operatorname{Re} \mathrm{d} t=\int_{0}^{\Delta t}\left(H_{\mathrm{R}} \cdot V_{\mathrm{r}}+H_{\mathrm{F}} \cdot A\right) \mathrm{d} t .
$$

O'Sullivan et al. (2010) listed the heat flow of some convective and conductive reservoirs in their work. These are used in our study to calculate the recharge in combination with information about the prevailing rock and its properties. 


\section{Technical parameters}

\section{Extracted heat}

The rate at which heat is extracted $E\left(\mathrm{~J} \mathrm{~s}^{-1}\right)$ is defined as the product of flow rate $Q$ $\left(\mathrm{m}^{3} \mathrm{~s}^{-1}\right)$, volumetric heat capacity of the heat-carrying fluid $c_{\mathrm{f}} \cdot \rho_{\mathrm{f}}\left(\mathrm{J} \mathrm{m}^{-3} \mathrm{~K}^{-1}\right)$, and the withdrawn temperature of the fluid before reinjection, $T_{\text {prod }}-T_{\text {reinj }}\left({ }^{\circ} \mathrm{C}\right)(\mathrm{Kohl}$ et al. 2008: 13):

$$
E=Q \cdot c_{\mathrm{f}} \cdot \rho_{\mathrm{f}} \cdot\left(T_{\text {prod }}-T_{\text {reinj }}\right) .
$$

\section{Conversion efficiency}

The conversion efficiency describes the quality of the conversion of heat into electrical energy. Because of the low temperature of produced fluids which are generally below $250{ }^{\circ} \mathrm{C}$, conventional geothermal power plants have low efficiency values of between 10 and 17\% (Barbier 2002: 41). In line with Jelacic et al. (2008: 6-7) we assume that energy conversion of EGS is equal to those of liquid-dominated hydrothermal resources at similar temperatures (flash steam and binary plants). O'Sullivan used efficiencies of 5-10\% for low- and high-enthalpy reservoirs, respectively. Zarrouk and Moon (2014) carried out a worldwide review using published data from 94 geothermal plants and came up with comparable results. Therefore, enthalpy-dependent net conversion values of between 5 and 15\% are considered suitable for the developed cases in the present study.

\section{Power generation}

The total electrical energy generated $E_{\mathrm{el}}(\mathrm{MWh})$ results from the extracted heat according to Eq. (5) with the respective conversion efficiency $\eta$ (\%) (Williams 2010: 2):

$$
E_{\mathrm{el}}=\eta \cdot \int_{0}^{\Delta t} E \mathrm{~d} t \cdot 2 . \dot{7} \cdot 10^{-10}
$$

\section{Well productivity}

According to Eq. (5), the flow rate is obviously critical to the extracted heat and, alongside temperature, a key factor determining economic viability (US Department of Energy 2009). However, rather than determining a value for $Q$ we leave this variable free, because it is the pivotal point of our optimization, and aim for determining a value of well productivity instead.

For wells in a conventional field, we can derive the typical flow rate by drawing on Stefansson (1992), during which he analyzed the result of drilling in 31 high-temperature geothermal fields across the world. He showed that the average yield of wells in any particular geothermal field is fairly constant after passing through a certain learning period and gaining sufficient knowledge about the reservoir to site the wells such that the maximum yield is achieved. He states that after this learning phase, which we account for by rising costs for the drilling of exploration wells, the average initial output per well is $4.2 \pm 2.2 \mathrm{MW}_{\mathrm{e}}$ (Stefansson 1992: 829). Sanyal (2004: 3) 
suggests a similar typical initial production of $5 \mathrm{MW}_{\mathrm{e}}$ per well which is corroborated by Thorhallsson and Sveinbjornsson (2012: 7). Our default values for a natural highenthalpy reservoir are therefore set to $\bar{w}=5 \mathrm{MW}_{\mathrm{e}}$ per well, while experience has shown that the output for an EGS reservoir is lower and estimated at $\bar{w}=1.5 \mathrm{MW}_{\mathrm{e}}$. This value can arguably be considered as fairly high, but our program includes drilling wells for exploration purposes that are not credited with productivity, so to some extent these effects cancel each other out.

\section{Production decline}

All wells in geothermal operation experience some sort of production decline, even if the reservoir is operated with reinjection, as the pressure is not equalized instantaneously from injection to production areas. In addition to decreasing pressure and declining temperature at the production well, mineral precipitation further enhances this effect (White et al. 1971). Even if a generalization of declining electrical output that can be realized through a well and the respective conversion technology is difficult, Sanyal et al. (2000) introduced an approximation equation. Just like wells in the oil industry (cf. Fetkovich 1980), geothermal production wells undergo a harmonic decline over time (Sanyal et al. 1989), following:

$$
W_{t}=\frac{W_{\mathrm{i}}}{1+D_{\mathrm{i}, t}},
$$

where $W_{\mathrm{i}}$ is the initial productivity, $D_{\mathrm{i}}$ is the initial annual decline rate and $W_{t}$ is the productivity in year $t$. The harmonic decline trend implies a decline rate that slows down over time, the annual decline rate $D_{t}$ of productivity in year $t$ being given by (Sanyal et al. 1989):

$$
D_{t}=\frac{D_{\mathrm{i}}}{1+D_{\mathrm{i}, t}} .
$$

In most cases the decline rate increases with installed capacity. This sensitivity of productivity decline to installed capacity is too site-specific to be quantified by a generally applicable correlation. Nevertheless, Sanyal et al. (2000) suggested an approximate formulation:

$$
D_{\mathrm{i}}^{\prime}=\left(\frac{W_{\mathrm{i}}^{\prime}}{W_{\mathrm{i}}}\right)\left(\frac{\ln W_{\mathrm{i}}^{\prime}}{\ln W_{\mathrm{i}}}\right) D_{\mathrm{i}}
$$

where $D_{\mathrm{i}}$ is the initial annual harmonic decline rate when the total production rate is $W_{\mathrm{i}}$, and $D_{\mathrm{i}}^{\prime}$ is the resulting initial annual harmonic decline rate when the total production rate is changed to $W_{\mathrm{i}}^{\prime}$. Assuming a typical initial harmonic decline rate of $5 \%$ for a specific reference capacity, the initial annual harmonic decline rate for any other plant capacity is estimated from Eq. (9). To keep production stable throughout the reservoir lifetime of the power plant, a simplified assumption is made that makeup drilling is performed at evenly distributed time intervals from the beginning to the end of operation. Further information on the implementation is provided when addressing subsurface costs later on. 


\section{Reservoir lifetime}

Starting point for the assessment of the endogenously determined reservoir lifetime is the recoverable HIP, $S_{\mathrm{R}}(\mathrm{J})$, which is governed by Eq. (3). While this initial stock is resupplied from the natural recharge $\operatorname{Re}\left(\mathrm{J} \mathrm{s}^{-1}\right)$ (Eq. 4), it is extracted in dependence of the applied extraction rate $E\left(\mathrm{~J} \mathrm{~s}^{-1}\right)$ (Eq. 7). This means that the rate of change of the HIP can be expressed as follows:

$$
\dot{S}_{\mathrm{R}}=E-R e .
$$

Operating time $\Delta t(\mathrm{~s})$ results from the time required to extract the recoverable heat while being counteracted by the recharge. Integration of the extraction and recharge rates over the life of the reservoir results in values for the total extraction and the total natural recharge which together must ultimately correspond to the recoverable heat content:

$$
S_{\mathrm{R}}=\int_{0}^{\Delta t} E \mathrm{~d} t-\int_{0}^{\Delta t} \operatorname{Re} \mathrm{d} t .
$$

It should be noted that the total extraction is equal to the initial stock plus the total recharge, as shown in Eq. (12), and is thus more than what is considered recoverable at the beginning:

$$
\int_{0}^{\Delta t} E \mathrm{~d} t=S_{R}-\int_{0}^{\Delta t} \operatorname{Re} \mathrm{d} t .
$$

This means that because a lower extraction rate results in a longer lifetime, the total amount of energy produced increases. Depending on the natural recharge this value can be significant. Since the model works with constant extraction rates, due to the fact that we counteract the production decline by accounting for drilling make-up wells (see "Production decline"), lifetime of the reservoir $\Delta t$ (s) can be calculated from Eq. (12) as:

$$
\Delta t=S_{\mathrm{R}} /(E-R e)
$$

\section{Reinjection}

Reinjection in geothermal activities has been used for a long time (Stefansson 1997). Often, more than $95 \%$ of the fluid produced is reinjected into the reservoir, limiting pressure losses while ensuring that a heat carrier is present (Barbier 2002: 19). As a standard practice, reinjection wells are located at lower elevation than the production wells, making the use of reinjection pumps dispensable. In cases where this is not applicable, due to topographic constraints and reservoir characteristics, the use of reinjection pumps becomes part of the production facilities (Kohl et al. 2008: 75-76). In our model, however, we assume the former, namely that a sufficient height difference can be realized, and injection is effective without using additional pumping force.

Considering Eq. (5), notice that the injection temperature represents a decisive role for the heat extracted. Typical injection temperatures for power plants focusing purely on electricity generation are in the range of $40{ }^{\circ} \mathrm{C}$ to $80{ }^{\circ} \mathrm{C}$ (Gerber and Maréchal 2012: 
911; Kohl et al. 2008: 28; Mouchot et al. 2019: 2), depending on the plant type and cooling system. Furthermore, we assume that the locations of the injection wells are chosen at a sufficient distance from the production wells in order to avoid premature thermal breakthrough.

\section{Capacity factor}

The capacity factor (cap) of a geothermal power plant is very high due to the independence of climate and seasonality (Stefansson 2002: 266) and usually reaches values well above $90 \%$. Reasons for such an exceptional capacity factor, besides the above-mentioned ones, are the base-load nature of geothermal energy, the absence of a fuel cycle, and the relatively modest temperature and pressure under which geothermal power plants operate, resulting in low stress on materials and therefore requiring less maintenance (Chamorro et al. 2012: 11). Accordingly, we use a capacity factor of $95 \%$ for our calculations, which seems to be appropriate for modern-day geothermal power plants and represents a frequently used value in economic calculations (Nathwani and Mines 2015).

\section{Economic parameters}

\section{Costs}

The investment costs of geothermal power plants are usually divided into the cost of surface and subsurface investment.

Surface investment: surface investment in this case describes the investment required for the power plant and gathering system. From the many studies on this subject, we have chosen the formulation by Chamorro et al. (2012: 17), which is based on economies of scale and deals with capital costs in the range of 1000-2000 US\$/kW for a corresponding capacity of between $5-150 \mathrm{MW}_{\mathrm{e}}$ for flash and dry stream power plants:

$$
C_{\text {surf }_{\text {spec }}}=2000 \cdot \exp [-0.0045 \cdot(W-5)] .
$$

Since the installation costs of binary plants are typically higher (Augustine et al. 2012: 13; Kohl et al. 2008: 73), we have to consider an alternative function for the installation costs for this type:

$$
C_{\text {surf }_{\text {spec }}}=3000 \cdot \exp [-0.008 \cdot(W-1)] .
$$

Equation (15) results in installation costs of between 2285 and 3000 US $\$ / k W$ for a binary plant with a capacity in the range of $1-35 \mathrm{MW}_{\mathrm{e}}$.

Subsurface investment: While in some studies, due to the uncertainty about geological properties, the subsurface costs are implemented only as a percentage of the total investment cost (e.g., Chamorro et al. 2012 assuming a 50\% share, hence equal to surface investment), we attempt to specify these costs by calculating the number of wells necessary for a targeted capacity and determine the drilling costs via the reservoir properties such as depth, or whether it is an EGS, which incurs additional costs for reservoir stimulation.

Costs per well: The cost estimation is based on the work of Lukawski et al. (2014). Equation (16) entails an exponential increase in cost with depth: 


$$
C_{\text {well }}=\left(1.72 \cdot 10^{-7} \cdot(M D)^{2}+2.3 \cdot 10^{-3} \cdot M D-0.62\right) \cdot 10^{6},
$$

where $C_{\text {well }}$ (US\$) are the well costs and MD $(\mathrm{m})$ is the measured depth.

In the case of an EGS we need to account for reservoir/well stimulation; the GETEM proposes a fixed value of US\$2.4 million per well stimulation, independent of depth (EERE 2016). Using this value, we specify the EGS well cost function as:

$$
C_{\text {EGSwell }}=\left(1.72 \cdot 10^{-7} \cdot(M D)^{2}+2.3 \cdot 10^{-3} \cdot M D+1.78\right) \cdot 10^{6} .
$$

Number of wells required (initial and make-up wells): The following equation reflects the initial number of wells required $N_{\mathrm{W}}$ for a constant given plant capacity $W$ $\left(\mathrm{MW}_{\mathrm{e}}\right)$ with a reserve factor $r$ of up to $T$ years in dependence of the initial annual harmonic decline rate $D_{\mathrm{i}}$ (Sanyal 2004: 3):

$$
T=\frac{1}{D_{\mathrm{i}}}\left[\frac{\bar{w} \cdot N_{\mathrm{w}}}{(1+r / 100) W}-1\right] .
$$

Equation (18) is used to derive a formulation for the number of wells required. However, since the reservoir lifetime results from the optimization with respect to the production rate, it is not known how many wells will be necessary from the outset. Nevertheless, the initial number of wells required, $N_{\text {wi }}$, can be calculated in a straightforward manner using Eq. (19), with $W\left(\mathrm{MW}_{\mathrm{e}}\right)$ being total plant capacity and $\bar{w}\left(\mathrm{MW}_{\mathrm{e}}\right)$ being the average capacity per well:

$$
N_{\mathrm{wi}}=W / \bar{w} .
$$

This results in subsurface costs of:

$$
C_{\text {subsurf }}=C_{\mathrm{well}} \cdot N_{\mathrm{wi}} \text {. }
$$

Further, reformulation of Eq. (18) yields Eq. (21), which gives the total number of wells required for the entire lifetime of the reservoir. Note that both $T$ and $W$, as well as the production decline rate $D_{\mathrm{i}}^{\prime}$ from Eq. (9), are, as with any other function specified, ultimately in dependence of the extraction flow $Q\left(\mathrm{~m}^{3} \mathrm{~s}^{-1}\right)$ :

$$
N_{\mathrm{w}}=\frac{\left(1+T \cdot D_{\mathrm{i}}^{\prime}\right) \cdot(W+W \cdot r / 100)}{\bar{w}} .
$$

Knowing both the total number of wells necessary and the number of initial wells required, Eq. (22) can be used for calculating the number of make-up wells $N_{\text {wu }}$ necessary to keep production on a constant level throughout the lifetime of the reservoir:

$$
N_{\mathrm{wu}}=N_{\mathrm{w}}-N_{\mathrm{wi}} \text {. }
$$

The reason why we are interested in dividing the initial number of wells and the number of make-up wells is because the costs of the latter are incurred in later periods and must be discounted accordingly. Equation (23) determines the discounted development costs of make-up wells, with $i$ being the interest rate, for an even 
distribution of the make-up drillings over the lifetime of the reservoir starting after year one:

$$
C_{\text {makeup }}=\int_{1}^{T} C_{\text {well }} \cdot \frac{N_{\text {wu }}}{T} \cdot e^{-i t} \mathrm{~d}
$$

Operation and maintenance: The operation and maintenance (O\&M) costs are assumed to be proportional to the energy production, and follow an exponential decline with increasing plant capacity (Sanyal 2004: 2). Equation (24) reflects the specific O\&M costs $C_{\mathrm{O} \& \mathrm{M}_{\text {spec }}}(\mathrm{US} \$ / \mathrm{MWh})$ as a function of the installed capacity $W\left(\mathrm{MW}_{\mathrm{e}}\right)($ Chamorro et al. 2012: 17):

$$
C_{O \& M_{\text {spec }}}=20 \cdot \exp [-0.0025 \cdot(W-5)] .
$$

This results in O\&M costs that exponentially decrease from 20 US\$/MWh for a $5 \mathrm{MW}_{\mathrm{e}}$ plant to $14 \mathrm{US} \$ / \mathrm{MWh}$ for a $150 \mathrm{MW}_{\mathrm{e}}$ plant.

Exploration and permitting: Additionally, we have to account for exploration and permitting costs. Up-front drilling for exploration is required to locate potential well placements in a greenfield and therefore includes drilling costs and leasing costs, respectively. The GETEM suggests a default of drilling one small diameter well (20\% cheaper) for initial development of the site (EERE 2016). This is then followed by drilling two more full-sized wells to gather information and allowing each following well drilled to be successful, which substantiates our assumption of a constant average well productivity. Using Eq. (25) we can build up our costs for exploration and permitting by using a cost multiplier of $20 \%$ to account for permitting and leasing:

$$
C_{\mathrm{E \& P}}=1.2 \cdot 2.8 \cdot C_{\mathrm{well}} \text {. }
$$

\section{Revenues}

Revenues $P(€)$ are calculated on the basis of the electrical output generated $E_{\mathrm{el}}$ (MWh) and the corresponding electricity price $p\left(€ \mathrm{MWh}^{-1}\right)$ :

$$
P=p \cdot E_{\mathrm{el}} .
$$

Values in our calculations are oriented towards the current German wholesale dayahead spot market with an electricity price of around $50 € / M W h$ (EPEX 2019) and the German feed-in tariff for geothermal sources of $240 € / M W h$ (BDEW 2017: 36). All aforementioned cost values US dollars are converted into $€$ using the official exchange rate of 0.88 (as of 20 February 2019).

\section{Objective function}

The main objective for the endogenized lifetime model proposed is to express the optimal exploitation of the stock from an economic perspective, subject to the plant operator's control of the flow rate, $Q$, and the installed capacity, $W$. That way, we include the temporal component as a free value, rather than assuming a fixed lifetime, which is the 
main idea of this model and initially inspired by the theory of optimal resource extraction as described by Perman et al. (2003). In summary, we can specify the NPV as a function of $Q$ :

$$
\begin{aligned}
\operatorname{NPV}(Q)= & -C_{\text {E\&P }}-C_{\text {surf }}-C_{\text {subsurf }}-C_{\text {makeup }} \\
& +\int_{0}^{T}\left(P_{\text {annual }}-C_{\mathrm{O} \& \mathrm{M}, \text { annual }}\right) \cdot e^{-i t} \mathrm{~d} t .
\end{aligned}
$$

The constrained optimization problem is solved (using MATLAB) in order to determine the maximum NPV-within the boundaries of 5-150 $\mathrm{MW}_{\mathrm{e}}$ for a natural geothermal system (Case 1) and 1-35 MW for an EGS (Case 2), respectively.

Additionally, we calculate the levelized cost of electricity (LCOE) $(€ / \mathrm{kWh})$ as a present value measure of the average total cost to build, operate and maintain the geothermal power plant over its entire, endogenously determined lifetime, divided by the total (cumulative) energy output over the expected lifetime (Pawel 2014: 69):

$$
\mathrm{LCOE}=\frac{C_{\mathrm{E} \& \mathrm{P}}+C_{\text {surf }}+C_{\text {subsurf }}+C_{\text {Makeup }}+\int_{0}^{T} C_{\mathrm{O} \& \mathrm{M}, \text { annual }} \cdot e^{-i t} \mathrm{~d} t}{\int_{0}^{T} W \cdot \text { cap } \cdot 8760 \cdot 10^{3} \cdot e^{i t} \mathrm{~d} t} .
$$

\section{Case studies}

The two exemplary cases analyzed with the hybrid model are described next, followed by the application of the model and a detailed sensitivity analysis of key parameters. A broad range of data has been collected from several publications, whereas others have already been discussed and explained above. Together, two different exemplary cases, which are the starting point for the economic evaluation, are created. The reservoirs are chosen to reflect the two extremes for the use of geothermal energy for electricity production. One is a convective high-enthalpy hydrothermal reservoir of moderate depth, i.e., an ideal natural geothermal system. The other reservoir reflects the case of a deep petrothermal unconventional system based on conductivity, i.e., an HDR system. By looking at the two extremes, we can determine more precisely to what extent the use of new geothermal energy sources differs from that of conventional energy sources. This refers to the extent to which certain parameters influence cost effectiveness, and what statements can be made about sustainable operation as previously discussed.

\section{Case study description}

\section{Case 1: Conventional (convective high-enthalpy hydrothermal) system}

Case 1 is oriented towards the Wairakei-Tauhara geothermal system and reflects a liquid-dominated high-enthalpy reservoir with a strong convective energy recharge (O'Sullivan et al. 2010: 315). The bedrock consists of rhyolite (Bignall et al. 2010) and the values for density, heat capacity and heat production from radiogenic decay of the reservoir rock were chosen accordingly. Drilling depth is set to $1500 \mathrm{~m}$, as reported by Bignall et al. (2010: 6). Porosity is determined to be $20 \%$ and temperature reaches values as high as $270{ }^{\circ} \mathrm{C}$ (Björnsson and Bodvarsson 1990: 19). We assume that temperature of the produced fluid is lower and suggest a value of $260{ }^{\circ} \mathrm{C}$, while the temperature of reinjected 
water is set to $65{ }^{\circ} \mathrm{C}$. Because of the relatively high temperature, we choose a net conversion efficiency of $14 \%$ based on previous analysis. Average well productivity is set at $5 \mathrm{MW}_{\mathrm{e}}$ per well and due to the strong convective recharge of the field of $13.3 \mathrm{~W} \mathrm{~m}^{-2}$, we raise the reference capacity for a $5 \%$ annual decline to $100 \mathrm{MW}_{\mathrm{e}}$. Note that because of the large surface area $\left(30 \mathrm{~km}^{2}\right)$, we assumed the reservoir to be quite thin $(150 \mathrm{~m})$, as we wanted to stay in the range of a $150 \mathrm{MW}_{\mathrm{e}}$ power plant during our optimization model runs in order not to violate cost constraints, while at the same time maintaining the properties of the heavy recharge. Based on our findings, we select a recovery factor of $20 \%$ (see "Recovery factor"). These and all other values used for the optimization are listed in Table 3.

\section{Case 2: Enhanced (conductive low-enthalpy petrothermal) system}

Case 2 to some extent resembles the prominent EGS project Soultz-sous-Forêts in France (Alsace). Its reservoir is located at a depth of 3500-5000 m (Moeck 2014: 875) and is composed of granite (Moeck 2014: 878). Reservoir temperature averages at $180{ }^{\circ} \mathrm{C}$ (Gerard and Kappelmeyer 1987: 399) and water is produced and reinjected at temperatures of $175{ }^{\circ} \mathrm{C}$ and $65^{\circ} \mathrm{C}$, respectively (Bine.info 2009). The reservoir volume amounts to $3 \mathrm{~km}^{3}$, with a base area of $3 \mathrm{~km}^{2}$ (Bine.info 2009), and has a low porosity of 1\% (Moeck 2014: 878). Further values can be found in Table 3. As the idea is to model a pure petrothermal system, some of the values originate from the HDR project Cooper Basin (South Australia), because the energy recharge at the Soultz-sous-Forêts site is also sustained by a convective flow.

\section{Optimization and implications}

In this section, the economic feasibility of the two reservoirs is assessed in terms of the NPV and the LCOE. Furthermore, initial findings on sustainable production are presented. Running the model with the parameter values reported in Table 3 results in the following optimizations.

\section{Case 1}

Figure 3a shows that for the selected parameters an installed capacity of $126.7 \mathrm{MW}$ results in a maximum NPV of $€ 196.04$ million, and that the LCOE amount to $2.93 €$-ct/ $\mathrm{kWh}$. The remarkably low value of the latter is due to the ideal qualities of the reservoir, characterized by moderate depth, high temperatures (and thus a relatively high conversion factor), a strong recharge (and thus relatively moderate production decline), and the possibility of exploiting economies of scale. LCOE in the vicinity of $3 €$-ct $/ \mathrm{kWh}$ is a common value for natural geothermal reservoirs with excellent conditions (Kohl et al. 2008: 74; Bertani et al. 2018: 9). However, with this performance (which is constantly maintained by new make-up wells) the reservoir would already be exhausted after 41.2 years of production. Nevertheless, due to its large surface area and thus extremely high recharge of almost $400 \mathrm{MW}$ in total, the withdrawn energy would be restored only after roughly 50 years.

Through the fictitious assumption about the reservoir regarding the ratio of surface to overall volume we have created an ideal reservoir that is referred to in the literature as 
Table 3 Parametrization for Case 1 (conventional geothermal system) and Case 2 (enhanced geothermal system)

\begin{tabular}{|c|c|c|c|c|c|}
\hline Parameter & Symbol & Case 1 & Case 2 & Unit & Source/section \\
\hline $\begin{array}{l}\text { Thermal capacity of reservoir } \\
\text { rock }\end{array}$ & $c_{r}$ & 800 & 1000 & $\left(\mathrm{~kg}^{-1} \mathrm{~K}^{-1}\right)$ & $\begin{array}{l}\text { Proske (undated: 7) } \\
\text { Stober and Bucher (2014: 10) }\end{array}$ \\
\hline Density of reservoir rock & $\rho_{\mathrm{r}}$ & 2600 & 2700 & $\left(\mathrm{~kg} \mathrm{~m}^{-3}\right)$ & Proske (undated: 7) \\
\hline Specific thermal capacity of fluid & $c_{f}$ & 4120 & 4120 & $\left(\mathrm{~J} \mathrm{~kg}^{-1} \mathrm{~K}^{-1}\right)$ & - \\
\hline Density of heat carrying fluid & $\rho_{\mathrm{f}}$ & 1000 & 1000 & $\left(\mathrm{~kg} \mathrm{~m}^{-3}\right)$ & - \\
\hline Porosity & $\Phi$ & 20 & 1 & (\%) & $\begin{array}{l}\text { Björnsson and Bodvarsson (1990: } \\
\text { 19) } \\
\text { Moeck (2014: 878) }\end{array}$ \\
\hline Reservoir volume & V & $4.5 \cdot 10^{9}$ & $3 \cdot 10^{9}$ & $\left(m^{3}\right)$ & $\begin{array}{l}- \\
\text { Bine.info (2009) }\end{array}$ \\
\hline Reservoir temperature & $T_{\mathrm{R}}$ & 270 & 180 & $\left({ }^{\circ} \mathrm{C}\right)$ & $\begin{array}{l}\text { Björnsson and Bodvarsson (1990: } \\
\text { 19) } \\
\text { Gerard and Kappelmeyer (1987: } \\
\text { 399) }\end{array}$ \\
\hline Surface temperature & $T_{\mathrm{S}}$ & 14 & 14 & $\left({ }^{\circ} \mathrm{C}\right)$ & Walter (2016: 7) \\
\hline Measured drilling depth & $M D$ & 1500 & 4000 & (m) & $\begin{array}{l}\text { Bignall et al. (2010: 6) } \\
\text { Moeck (2014: 875) }\end{array}$ \\
\hline Recovery factor & $R$ & 20 & 5 & (\%) & cf. "Recovery factor" \\
\hline Temperature of produced fluid & $T_{\text {prod }}$ & 260 & 175 & $\left({ }^{\circ} \mathrm{C}\right)$ & $\begin{array}{l}\text { Björnsson and Bodvarsson (1990: } \\
\text { 19) bine.info (2009) }\end{array}$ \\
\hline Temperature of reinjected fluid & $T_{\text {rein } j}$ & 65 & 65 & $\left({ }^{\circ} \mathrm{C}\right)$ & $\begin{array}{l}\text { cf."Reinjection” } \\
\text { Bine.info (2009) }\end{array}$ \\
\hline Heat from radioactive decay & $H_{R}$ & $2.7 \cdot 10^{-6}$ & $3 \cdot 10^{-6}$ & $\left(\mathrm{~W} \mathrm{~m}^{-3}\right)$ & $\begin{array}{l}\text { Hasterok and Webb (2017: 925) } \\
\text { Rybach (1976) }\end{array}$ \\
\hline Heat flow from earth's interior & $H_{F}$ & 13.3 & $0.105^{c}$ & $\left(\mathrm{~W} \mathrm{~m}^{-2}\right)$ & O'Sullivan et al. (2010: 315) \\
\hline Reservoir surface area & $A$ & $3 \cdot 10^{7}$ & $3 \cdot 10^{6}$ & $\left(m^{2}\right)$ & $\begin{array}{l}\text { O'Sullivan et al. (2010: 315) } \\
\text { Bine.info (2009) }\end{array}$ \\
\hline Net conversion efficiency & $\eta$ & 14 & 8 & $(\%)$ & cf. "Conversion efficiency" \\
\hline Average productivity per well & $\bar{W}$ & 5 & 1.5 & $\left(\mathrm{MW}_{\mathrm{e}}\right)$ & cf."Well productivity" \\
\hline Electricity price/feed-in tariff & $p$ & 50 & $240^{d}$ & $\left(€ \mathrm{MWh}^{-1}\right)$ & $\begin{array}{l}\operatorname{EEX}(2019) \\
\operatorname{BDEW}(2017: 36)\end{array}$ \\
\hline Discount rate & $i$ & 5 & 5 & $(\%)$ & - \\
\hline $\begin{array}{l}\text { Reference initial production } \\
\text { decline rate }\end{array}$ & $D_{\mathrm{i}}$ & 5 & 5 & $(\%)$ & cf."Production decline" \\
\hline Reference initial capacity ${ }^{\mathrm{a}}$ & $W_{i}$ & 100 & 25 & $\left(\mathrm{MW}_{\mathrm{e}}\right)$ & cf."Production decline" \\
\hline Well reserve factor & $r$ & 10 & 0 & $(\%)$ & cf."Production decline" \\
\hline Tax rate & $\operatorname{tax}$ & $20^{\mathrm{b}}$ & $-^{\mathrm{e}}$ & (\%) & - \\
\hline $\begin{array}{l}\text { Surrounding thermal compen- } \\
\text { sation }\end{array}$ & $\beta$ & 1 & 6 & $(\%)$ & cf. "Recovery factor" \\
\hline Plant type & & Flash & Binary & & $\begin{array}{l}\text { O'Sullivan et al. (2010: 315) } \\
\text { Bine.info (2009) }\end{array}$ \\
\hline Capacity factor & cap & 0.95 & 0.95 & $(\%)$ & cf."Capacity factor" \\
\hline Start for make-up well drilling & & 1 & 1 & (a) & $\begin{array}{l}\text { cf. "Costs (Number of wells } \\
\text { required)" }\end{array}$ \\
\hline
\end{tabular}

a Due to the strong convective setting, reference production decline capacity was set to $100 \mathrm{MW}_{\mathrm{e}}$

b We chose a very moderate tax rate, as the model currently does not take into account realization of tax savings

c Value of the heat flow from Cooper Basin, an HDR project in South Australia (O'Sullivan et al. 2010: 315)

${ }^{d}$ Case 2 is calculated with the current German feed-in tariff for geothermal electricity as normal electricity prices were not sufficient for profitable operation

e Taxes have been neglected for Case 2 

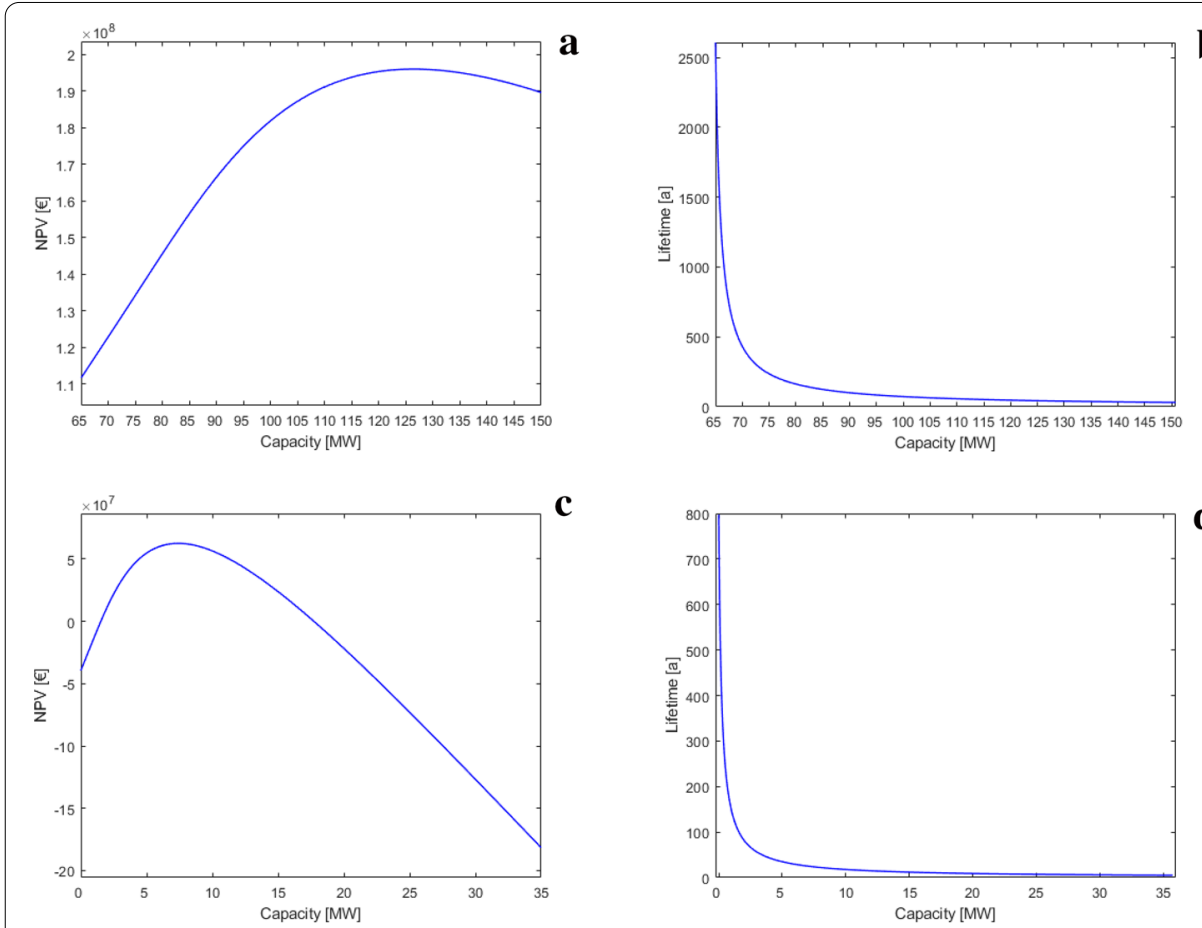

Fig. 3 NPV and reservoir lifetime in dependence of installed capacity. a NPV as a function of installed capacity (Case 1); b lifetime as a function of capacity (Case 1); c NPV as a function of installed capacity (Case 2); $\mathbf{d}$ lifetime as a function of capacity (Case 2)

'renewable', since an excessive production also leads to a renewal of the reservoir within the same order of time. Optionally, the reservoir could also be used cyclically, the alternative being a permanent, truly sustainable operation that meets the condition $E=R e$. This condition would correspond to an installed capacity of approx. $65 \mathrm{MW}_{\mathrm{e}}$ for the given case. By the rate of change of the stock $\dot{S}_{\mathrm{R}}=-E+R e$ the lifetime of the reservoir increases exponentially and approaches infinity, as illustrated in Fig. $3 \mathrm{~b}$.

After covering the two extremes of excessive and sustainable production, we want to focus on production in a sustainable manner. As a reminder: lifetimes between 100 and 300 years were suggested by different authors. For Case 1 this results in capacities between 89.96 and $72.83 \mathrm{MW}_{\mathrm{e}}$. This again reflects the strong recharge, as even a moderate reduction in capacity can extend the time until reservoir depletion occurs significantly (triple lifetime).

\section{Case 2}

Figure 3c shows that for the selected parameters an installed capacity of $7.7 \mathrm{MW}_{\mathrm{e}}$ results in a maximum NPV of $€ 62.65$ million, and a LCOE of $16.94 €$-ct $/ \mathrm{kWh}$, which again is very consistent with the values proposed in other studies (Campos Rodríguez et al. 2013: 118; Kohl et al. 2008: 78). The high value of the LCOE is made up of the increased costs for the installation, drilling and reservoir stimulation, as well as the lower temperatures resulting in lower conversion efficiencies, but also due to lower productivity of wells and poorer reservoir properties such as porosity, recharge and recovery factor. Note that the reservoir volume of Case 1 is only 50\% larger than the one for Case 2, making the 
Table 4 Production modes and results for Cases 1 and 2

\begin{tabular}{|c|c|c|c|c|c|c|}
\hline \multirow[t]{2}{*}{ Production mode } & \multicolumn{2}{|c|}{ NPV (million €) } & \multicolumn{2}{|c|}{ Capacity $\left(\mathrm{MW}_{\mathrm{e}}\right)$} & \multicolumn{2}{|c|}{$\begin{array}{l}\text { Reservoir lifetime } \\
\text { (a) }\end{array}$} \\
\hline & Case 1 & Case 2 & Case 1 & Case 2 & Case 1 & Case 2 \\
\hline Excessive production & 196.04 & 62.65 & 126.66 & 7.66 & 41.2 & 23.8 \\
\hline \multirow[t]{2}{*}{ Production in a sustainable manner } & 165.98 & 1.71 & 89.96 & 1.84 & 100 & \\
\hline & 128.77 & -29.54 & 72.83 & $0.63^{\mathrm{a}}$ & 300 & \\
\hline Sustainable production & 109.59 & -45.46 & 64.25 & $0.03^{\mathrm{a}}$ & Infinite & \\
\hline
\end{tabular}

a Values outside the defined range of the cost function, which results in a slight increase in both the surface and O\&M costs

divergence between the NPV results even more impressive considering that revenues (feed-in tariff) for Case 2 are almost five times as high and not subject to corporate tax. Altogether, this reflects the current status of EGS, namely that they cannot operate economically and/or sufficiently low financial risk, without guaranteed feed-in tariffs (in Germany, e.g., for 20 years). The lifetime of the presented case amounts to 23.8 years, which is a typical value for an EGS. Regeneration time is calculated to be approximately 7000 years.

Table 4 provides an overview of the different stages of operation for the discussed cases. Although all capacities result in a positive NPV for Case 1, it is apparent that the excessive operation is the most profitable one, as could already be seen in Fig. 3a. For Case 2, the only production mode linked to sustainability which results in a positive NPV is the production in a sustainable manner with a targeted capacity of approx. 1.8 $\mathrm{MW}_{\mathrm{e}}$, resulting in a reservoir lifetime of 100 years.

\section{Sensitivity analysis}

A sensitivity analysis is performed by a gradual $10 \%$ increase/decrease for the following parameters: average well productivity, production decline, ${ }^{2}$ interest rate, surface, subsurface $^{3}$ and O\&M costs as well as electricity price/feed-in tariff, respectively, for Cases 1 and 2. The variations of these parameters are compared to the NPV, LCOE, installed capacity and lifetime of the reservoir in order to identify the most influential one of them. Note that no parameters influenced by the optimization are kept as fixed, so that for each change the model was run again to find a new optimal solution. Furthermore, notice that the electricity price/feed-in tariff has not been changed all the way to $-50 \%$, since there would be no positive result and therefore the optimization leads to the conclusion that no operation is initiated. A similar effect can be observed for the installed capacity for Case 1, since the optimization requires an upper limit of $150 \mathrm{MW}_{\mathrm{e}}$, as the implemented cost functions are not supported beyond this range. This upperlimit boundary leads to some parameter curves apparently flattening out, a phenomenon which should be borne in mind when interpreting the results.

\footnotetext{
${ }^{2}$ This value refers to the initial reference production decline; resulting values are automatically calculated during optimization based on Eq. (9), see "Well productivity".

3 The subsurface costs in this case refer to the estimated costs for drilling a well and thus influence both the initial subsurface cost and the costs for make-up drilling.
} 


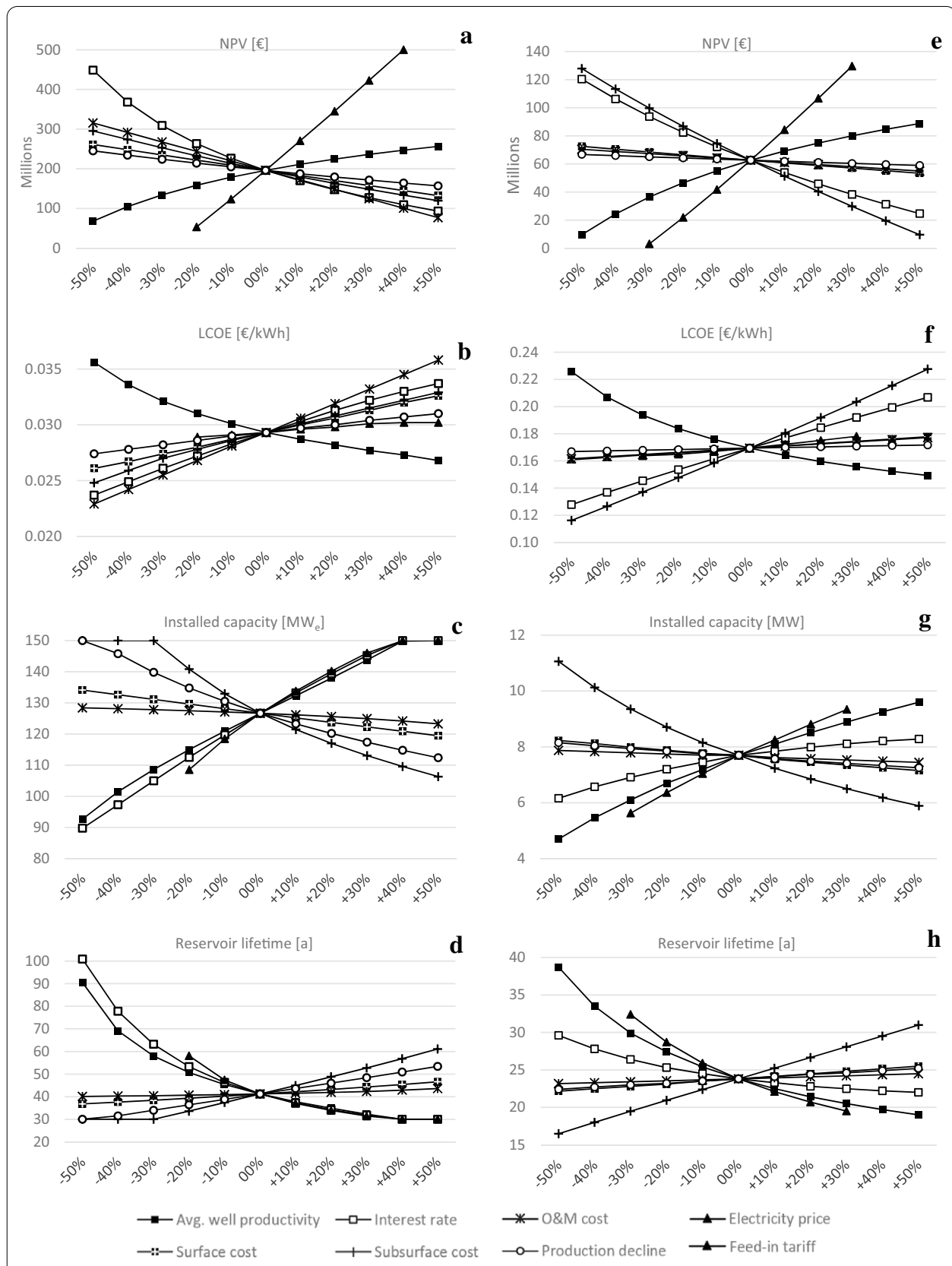

Fig. 4 Results of the sensitivity analysis for Case 1 (left plot) and Case 2 (right plot)

\section{Case 1}

Figure 4a depicts the NPV versus a percentage deviation in the values of the various independent variables from their initial value. A steeper curve through the base case point implies a higher sensitivity of the NPV with regard to the variable represented by the curve. Figure 4a clearly shows that the electricity price has the highest impact on the NPV. However, a decrease in the interest rate has a similarly strong effect for Case 1 . This is because a decreasing interest rate lowers the urge to achieve profits quickly, thus empowering the recharge capabilities of the reservoir, which in turn leads to more energy being produced 
over the plant's lifetime. Average well productivity and O\&M costs appear to have similar effects on the NPV but obviously in opposite directions. A +50\% variation for O\&M cost and $-50 \%$ variation for the average well productivity both result in an NPV of around $€ 70$ million for the given case. On the other side of the variation, however, O\&M costs have a larger influence. This connection is not quite apparent at first but can be explained in combination with the optimal installed capacity (cf. Fig. 4c). The reduction in O\&M costs has a more or less purely monetary effect, while an increase in average well productivity also has a significant effect on the optimal capacity, which in the dynamic nature of the model leads to an increased production decline and higher installation costs, which counteracts part of the cost savings. Surface and subsurface costs seem to have a roughly comparable impact on the NPV in the defined case. Out of all the parameters analyzed, production decline has the smallest impact.

Figure $4 \mathrm{~b}$ illustrates the influence of the parameters varied on the LCOE. Once again O\&M costs and average well productivity show a similarly strong but mirrored effect, which this time is higher than the influence of all other parameters. Notice that an increase in the electricity price actually leads to a slightly higher LCOE, which can be explained by the fact that the operator has an incentive to realize profits more quickly, and thus pursues a more aggressive production strategy which causes the cost per unit of energy produced to rise. The same explanation applies to the interest rate, but with much greater impact. The influence of a change in production decline is again found to be very minor. While surface and subsurface costs are again almost congruent in the 0 to $+50 \%$ direction, the influences on the 0 to $-50 \%$ side diverge.

Illustrating the influence on the installed capacity the upper bound of $150 \mathrm{MW}_{\mathrm{e}}$ is clearly reached for a couple of parameters. We have already stated that an increase in electricity price and interest rate will lead to a more excessive production scheme. The same applies to an increase in average well productivity as well as a decrease in the production decline.

A decrease in subsurface costs leads to a drastic increase in installed capacity, not only due to the fact that the subsurface costs account for a major part of the initial investment, but also because they have a reducing influence on further investments, which by nature of the model increase with capacity, namely the costs for make-up well drilling (see "Production decline"). Although the modeled production decline rises with increasing capacity, requiring more make-up wells to be drilled, these are in this case reduced in cost, with the result that economic optimization quickly leads to an installed capacity of $150 \mathrm{MW}_{\mathrm{e}}$. Interestingly, although the production decline had one of the least influential effects on NPV and LCOE, a decrease of $50 \%$ leads to the cap of an installed capacity of $150 \mathrm{MW}_{\mathrm{e}}$ due to the indirect cost savings related to drilling less make-up wells. Surface as well as O\&M costs are found to have the least impact on installed capacity. This can be explained by their nature (economies of scale), which means that an increase or decrease in costs is to some extent offset by the capacity realized (see "Costs").

The effect of the individual parameters on the lifetime of the reservoir is shown in Fig. $4 \mathrm{~d}$. Basically, it is a mirrored representation of the installed capacity, as the latter determines how long the reservoir can be operated. However, since the recharge counteracts the extraction, the rather linear image in Fig. $4 \mathrm{c}$ results in a reversed exponential distortion (recall Fig. 3b in this context). 


\section{Case 2}

Figure $4 \mathrm{e}$ presents the sensitivity analysis on the NPV for Case 2. Similarly to the electricity price in Case 1, a change in the feed-in tariff is very influential. Note that the feed-in tariff has only been changed to $-30 \%$ and $+30 \%$, as the former would result in a negative economic outcome and the latter would only unnecessarily distort the illustrations. In contrast to the natural geothermal system in Case 1, the HDR system in Case 2 shows a significantly higher sensitivity with regard to subsurface costs, which even exceeds the sensitivity related to the interest rate. This is not only because the wells have a lower productivity, but also because the costs of the wells in this case-due to the depth drilled and the additional stimulation required-are significantly higher. O\&M costs show a significantly lower impact, which is due to the fact that, in comparison to the revenues, they have a considerably lower effect than in Case 1, since the value of the feed-in tariff far exceeds the electricity price accounted for in Case 1. Average well productivity, in contrast, shows a very familiar influence on the NPV. Surface costs also show a slightly lower influence, which is due to the low realized capacity and thus results in a low absolute value.

Figure 4f, reflecting the sensitivity of the LCOE, again highlights the strong impact of the subsurface costs. It should be noted that, when disregarding economies of scale, O\&M costs have the same absolute impact in both cases, but appear marginal in Fig. $4 \mathrm{f}$ due to the fact that the LCOE for the HDR system is almost an order of magnitude higher compared to Case 1. For the same reason, the interest rate exceeds the latter, as it influences the revenues generated in a proportionate way and thus takes approximately the same relative position as in Case 1 . The change in the feed-in tariff again has only a minor relative impact on the LCOE, while the production decline in this case is almost insensitive. This in turn is due to the fact that the calculated production decline refers to a reference capacity of $25 \mathrm{MW}_{\mathrm{e}}$, which for all variations of the production decline is far undercut during optimization (see Fig. 4g). Figure 4g shows how insensitive the installed capacity is on some of the parameters in the case of our HDR system. O\&M costs as well as surface costs and production decline have hardly any influence, and even the interest rate shows only a moderate influence, which is in contrast to the effects observed in Case 1, due to the comparatively shorter lifetime and the weaker recharge capabilities. In addition to average well productivity and the feed-in tariff, subsurface costs again display the highest impact.

Remember that the sensitivity analysis on the reservoir lifetime is a distorted reflection of the installed capacity depending on the recharge characteristics of the reservoir. In contrast to the dependence observed in Case 1, Fig. 4h represents a much more uniform reversal than in Fig. 4g, since the recharge in this case is much lower and its exponential influence on the lifetime becomes most apparent for those parameters affecting capacity in the vicinity of $5 \mathrm{MW}_{\mathrm{e}}$ (cf. Fig. 3d), which in this case are the average well productivity and the feed-in tariff.

\section{Discussion of results}

The results of the sensitivity analysis provide comprehensible results which, however, vary greatly due to the different characteristics of the two cases. In order to gain deeper insights, we now take a closer look at individual plots and thus establish our connection 
to the topic of sustainable operation. Our main focus is on the installed capacity because, in conjunction with the recharge characteristics, it is the main influence on the longevity of the reservoir (cf. Fig. 3b, d). Evaluating the results of the sensitivity analysis, parameters that have a significant influence on the installed capacity (and therefore reservoir lifetime) can be identified. For Case 1, these main influential parameters are (in order of intensity): subsurface cost, price of electricity, interest rate, average well productivity, and production decline. For Case 2, the following ordering arises: subsurface cost, feedin tariff, and average well productivity. It has been shown that the interest rate does not have such a significant influence on the installed capacity, but it is nevertheless examined as well. By analyzing the individual plots, we can determine the extent to which the economic advantage of profit maximization exceeds compliance with the derived sustainability criteria.

Figure 5a-e shows the results of the optimization for a variation of the mentioned parameters by $\pm 50 \%$ for Case 1 . The two vertical lines in the plots represent the production within "sustainable manner boundaries" in the sense of 100 to 300 years of reservoir lifetime, while 'true' sustainability equals a capacity of approx. $65 \mathrm{MW}_{\mathrm{e}}$ for Case 1 .

The optimization plots demonstrate that the reservoir could in all cases pursue any type of sustainable operation and would nevertheless be economically viable. The deviation from the most profitable operation, however, varies greatly with the variation of the respective parameters. For the initial case, the relative deviations from the economic optimum depicted in Table 5 result.

Next, we discuss Fig. $5 \mathrm{c}$ in some more detail, as it represents the only plot where profit maximization actually matches with a criterion of sustainability (the economic optimum with an installed capacity of $\sim 90$ MWe corresponds to a production of 100 years). This is due to the high recharge, which, combined with a low interest rate, ensures that the reservoir is utilized in a more long-term manner in order to extract the additional regenerative energy. As the interest rate increases, the urge to realize profits in earlier periods rises alike and the optimal capacity increases accordingly.

Although the interest rate has a clearly positive effect in terms of sustainable operation, a lower social discount rate (compared to the market discount rate) cannot be applied as a policy instrument. Albeit this would result in more "sustainability investments" appearing attractive, projects would be undertaken which-due to a current lack of economic viability - would be likely to prove disadvantageous in the interests of people living in the future, as they would burden future generations with an artificially inflated (but from today's perspective uneconomical) capital stock. Assuming that the projects were financed exclusively by public debt, future generations would have to service a debt burden that could exceed the benefits of these projects. Thus a low social discount rate adopted that deviates from the market interest rate does not serve the interests of future generations, as it will not safeguard the future opportunities of society (Zweifel et al. 2017: 48).

Figure $6 \mathrm{a}-\mathrm{d}$ shows the results of the optimization for a variation of the previously mentioned parameters with a significant influence on installed capacity, and/or reservoir lifetime, for Case 2. In this case, the vertical line corresponds to the lower limit of "production in a sustainable manner", i.e., a lifetime of 100 years. Other sustainability criteria, i.e., upper bound and true sustainability, have been found to be non-compliant. 

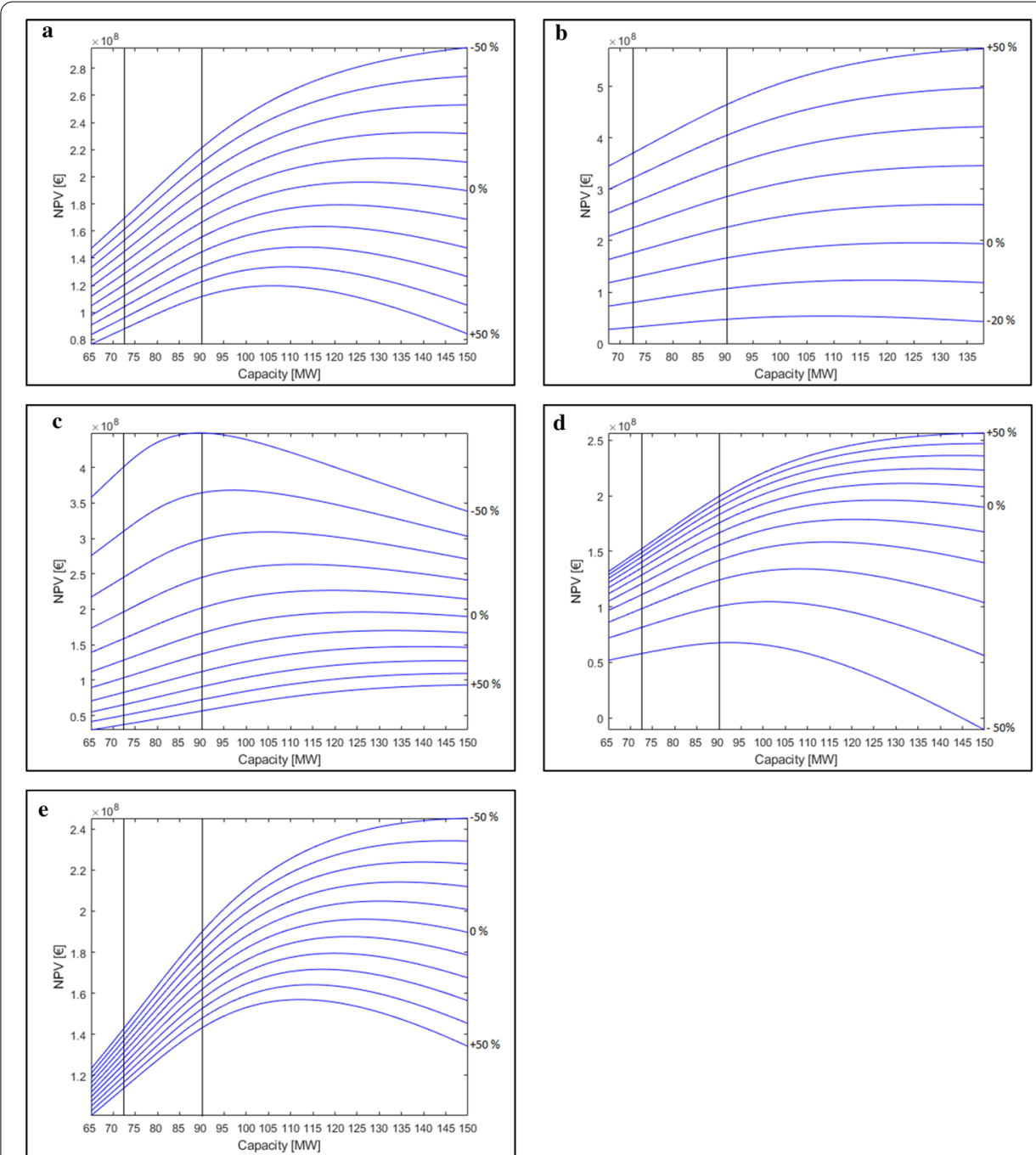

Fig. 5 Sensitivity analysis for key parameters on the optimization results - Case 1. The vertical lines represent the production within "sustainable manner boundaries" in the sense of 100 (right vertical line) to 300 years (left vertical line) of reservoir lifetime. $\mathbf{a}$ Variation of subsurface cost; $\mathbf{b}$ variation of electricity price; $\mathbf{c}$ variation of interest rate; $\mathbf{d}$ variation of average well productivity; $\mathbf{e}$ variation of production decline

The plots of the optimizations demonstrate that in quite a few cases a sustainable operation according to the lower boundary of the technical sustainability definition cannot be achieved, and is usually on the verge of profitability. The parameters used in the model result in the following economic limitations of sustainable operation (100 years of lifetime) for the defined HDR system: (a) an increase of subsurface cost greater than 10\%; (b) a decrease of feed-in tariff greater than $10 \%$; (c) a decrease of average well productivity greater than $30 \%$; and (d) an increase of the interest rate greater than $10 \%$. It is shown that the capacity does not change that much with the interest rate. This becomes apparent when considering that one of its main differences is the minor recharge.

The pursuit of a sustainable production with regard to the lower bound leads to a relative NPV deviation of - 97\% compared to the economic optimum for the initial Case 2, which is a remarkable difference in comparison to the conventional system (cf. Table 5). 

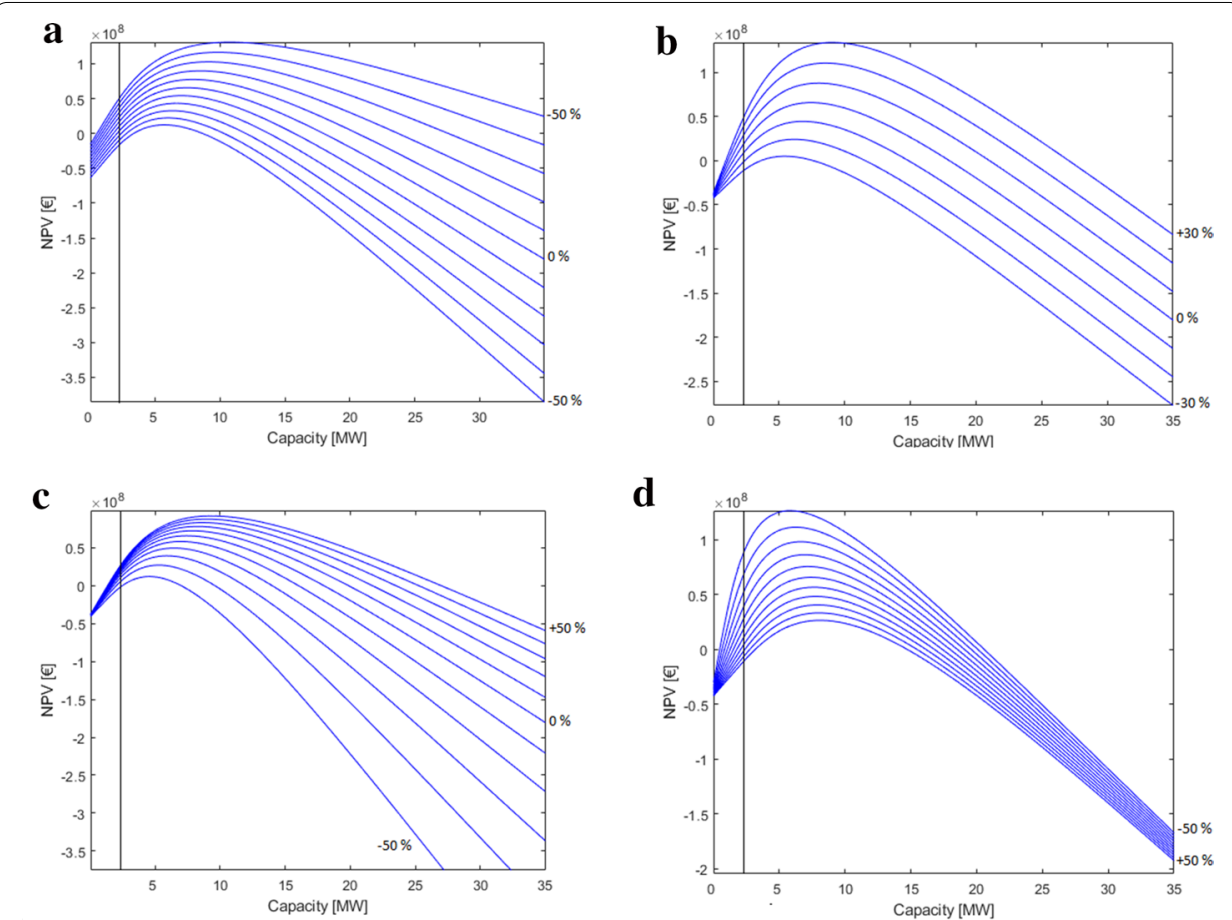

Fig. 6 Sensitivity analysis for key parameters on the optimization results-Case 2. The vertical line represents the production within "sustainable manner boundaries" in the sense of 100 years of reservoir lifetime. a Variation of subsurface cost; $\mathbf{b}$ variation of feed-in tariff; $\mathbf{c}$ variation of average well productivity; $\mathbf{d}$ variation of interest rate

Table 5 Deviation between sustainable and profit-maximizing production modes-Case 1

\begin{tabular}{ll}
\hline Production mode & $\begin{array}{l}\text { Deviation } \\
\text { from } N P V_{\max } \\
(\%)\end{array}$ \\
\hline $\begin{array}{l}\text { Production in a sustainable manner } \\
\text { Lower bound (100 years) }\end{array}$ & -15.3 \\
Upper bound (300 years) & -34.3 \\
Truly sustainable production & -44.1 \\
\hline
\end{tabular}

\section{Conclusion}

In this study, we developed a tool for the optimal utilization of geothermal resources and applied it on a convective high-enthalpy hydrothermal reservoir, as well as a lowenthalpy conductive petrothermal system. The developed model provides reasonable results for both systems, thus covering both extremes. The decisive difference to ordinary economic evaluations of geothermal resources is that the temporal component is treated as free (endogenous) instead of exogenously imposing a fixed lifetime. The implementation of various geological, technical and economic data results in a dynamic structure for the optimization of economic efficiency. The lifetime of the reservoir influenced by the optimization is the pivotal point for the discussion about a sustainable operation, which was discussed on the basis of existing literature. By carrying out a sensitivity analysis, we were able to identify not only those parameters 
that have an impact on economic performance, but also those that have a considerable influence on the installed capacity and the lifetime, respectively, and thus on the derived sustainability criteria. The reservoirs show very different sensitivities, which is due to the difference of the recharge capabilities and cost functions. In accordance with the related literature, the conventional system was found to be very economical, whereas the enhanced system can only be operated economically with a sufficiently high feed-in tariff. The LCOE for the two cases have been calculated at $2.93 €$-ct $/ \mathrm{kWh}$ and $16.94 €$-ct $/ \mathrm{kWh}$, respectively. Furthermore, the conventional system was found to be capable of meeting the sustainability criteria in almost all cases. These include the operation in an equilibrium between extraction and recharge as well as the technical definition of an operation time between 100 and 300 years. Economic optimization, however, leads to more excessive production schemes in all cases except for a macroeconomic climate dictated by a low interest rate, and thus reflects the behavior of modern-day power plant operations. The enhanced system, in contrast, could not do justice to a sustainable operation in most cases. Nevertheless, in the default case and within some slight variations of various parameter values, it can reach the lower threshold of our technical definition, i.e., it can operate over a lifetime of 100 years under the given circumstances, but is hardly economical. At this point, however, the question arises as to how useful this definition is for petrothermal systems. Accordingly, one could also argue to use the resource regardless of time. The earth's heat is inexhaustible from a human point of view, but conductive systems need a considerable time until they reach their pre-production status and are in that sense an exhaustible resource that should not be taken lightly.

Concluding, it should be noted that natural geothermal systems can be operated sustainably, but our optimizations show that a more excessive operation is generally economically beneficial. Artificially developed reservoirs for electricity generation that are purely sustained by a conductive heat flow are simply not economically viable or depend on high feed-in tariffs. With the more favorable reservoirs for EGS utilization that are also sustained by a conductive heat flow lying somewhere in between, it can be stated that these could be also operated in a sustainable manner, but again, without external influences, economic incentives would lead to excessive production.

\section{Abbreviations}

EGS: Enhanced geothermal system; GW: Gigawatt; HIP: Heat in place; HDR: Hot dry rock; kWh: Kilowatt-hours; LCOE: Levelized cost of electricity; MW: Megawatt; MWe: Megawatt electric; NPV: Net present value; ORC: Organic rankine cycle; PR: Production ratio; TW: Terawatt.

\section{List of symbols}

$\bar{W}$ : Average power output per well $\left(M W_{\mathrm{e}}\right) ; \eta$ : Conversion efficiency (\%); $C_{\text {E\&P: }}$ Cost for explor. and permitting $(€) ; C_{\text {makeup: }}$ Cost for make-up wells $(\epsilon)$; $C_{\text {well: }}$ Cost per well $(\epsilon) ; \rho$ : Density $\left(\mathrm{kg} \mathrm{m}^{-3}\right)$; $E_{e l}$ : Electrical energy (MWh); $p$ : Electricity price/feedin tariff $\left(€ \mathrm{MWh}^{-1}\right)$; E: Extraction rate $\left(\mathrm{J} \mathrm{s}^{-1}\right)$; $Q$ : Flow rate $\left(\mathrm{m}^{3} \mathrm{~s}^{-1}\right)$; $q$ : Heat flow $\left(\mathrm{J} \mathrm{s}^{-1} \mathrm{~m}^{-2}\right)$; $W$ : Installed capacity $(\mathrm{MW})$; $\mathrm{MD}$ : Measured depth (m); $N_{\text {wu: }}$ Number of make-up wells; $N_{w}$ : Number of wells total; $N_{w i}$ : Number of wells initially; $\Phi$ : Porosity (\%); D: Production decline (\%/a); $H_{\mathrm{R}}$ : Radiogenic heat production $\left(\mathrm{J} \mathrm{s}^{-1} \mathrm{~m}^{-3}\right)$; Re: Recharge rate $\left(\mathrm{J} \mathrm{s}{ }^{-1}\right) ; R$ : Recovery factor (\%); regen: Regeneration time (a); $\Delta t$ : Reservoir lifetime (s); P: Revenues from sales (€); $c$ : Specific heat capacity $\left(J \mathrm{~kg}^{-1} \mathrm{~K}^{-1}\right)$; $C_{0 \& M}$ spe: Specific O\&M cost $(€ / M W h) ; C_{\text {surf }}$ : Specific surface cost $(€ / k W)$; $S_{R}$ : Recoverable energy $(J)$; $A$ : Surface area $\left(\mathrm{m}^{2}\right)$; $T_{a}:$ Temperature of aquifer $\left({ }^{\circ} \mathrm{C}\right) ; T_{\text {prod: }}$ Temp. of produced fluid $\left({ }^{\circ} \mathrm{C}\right) ; T_{\text {rein: }}:$ Temp. of reinjected fluid $\left({ }^{\circ} \mathrm{C}\right) ; T_{\mathrm{s}}:$ Temperature of surface $\left({ }^{\circ} \mathrm{C}\right) ; \beta$ : Thermal compensation (\%); $\lambda$ : Thermal conductivity $\left(\mathrm{J} \mathrm{s}^{-1} \mathrm{~m}^{-1} \mathrm{~K}^{-1}\right) ; \mathrm{V}$ : Volume $\left(\mathrm{m}^{3}\right) ; S$ : Volumetric heat capacity $\left(\mathrm{J} \mathrm{m}^{-3} \mathrm{~K}^{-1}\right)$; $r$ : Well reserve factor $(\%)$. 


\section{Authors' contributions}

FH: conceptualization, data curation, formal analysis, investigation, methodology, validation, visualization, writing —original draft. RM: conceptualization, investigation, methodology, supervision, validation, visualization, writing - review and editing. Both authors read and approved the final manuscript.

\section{Funding}

Open Access funding enabled and organized by Projekt DEAL. The authors received no dedicated funding for conducting the study.

\section{Availability of data and materials}

Data supporting the findings are available from the authors upon request.

\section{Ethics approval and consent to participate}

Not applicable.

\section{Consent for publication}

Not applicable.

\section{Competing interests}

There are no competing interests.

\section{Author details}

${ }^{1}$ RWTH Aachen University, Templergraben 55, 52056 Aachen, Germany. ${ }^{2}$ Institute for Future Energy Consumer Needs and Behavior (FCN), School of Business and Economics / E.ON Energy Research Center, RWTH Aachen University, Mathieustrasse 10, 52074 Aachen, Germany. ${ }^{3}$ Department of Industrial Economics and Technology Management, Norwegian University of Science and Technology (NTNU), Sentralbygg 1, Gløshaugen, 7491 Trondheim, Norway.

Received: 7 September 2020 Accepted: 2 January 2021

Published online: 15 March 2021

\section{References}

Augustine C, Denholm P, Heath G, Mai T, Tegen S, Young K. Renewable electricity futures study. Volume 2: Renewable electricity generation and storage technologies_Chapter 7. Geothermal energy technologies. Golden, CO: National Renewable Energy Laboratory (NREL); 2012.

Axelsson G, Stefánsson V. Sustainable management of geothermal resources. In: International Geothermal Conference. Reykjavik, Iceland, Sept; 2003.

Axelsson G, Stefánsson V, Björnsson G, Liu J. Sustainable management of geothermal resources and utilization for 100-300 years. In: Proceedings of the world geothermal congress, Antalya, Turkey, 24-29 April 2005.

Axelsson G, Bromley C, Mongillo M, Rybach L. The sustainability task of the international energy agency's geothermal implementing agreement. In: Proceedings of the world geothermal congress, Bali, Indonesia, 25-29 April 2010.

Barbier E. Geothermal energy technology and current status - an overview. Renew Sustain Energy Rev. 2002;6(1):3-65.

Bauer M. Energiewirtschaft 2014_Fakten und Chancen der Tiefen Geothermie. Wiesbaden: Springer Spektrum; 2014a. https://doi.org/10.1007/978-3-658-06409-9.

Bauer M. Handbuch Tiefe Geothermie—Prospektion, Exploration, Realisierung, Nutzung. Berlin, Heidelberg: Springer Spektrum; 2014b. https://doi.org/10.1007/978-3-642-54511-5.

BDEW. Erneuerbare Energien und das EEG: Zahlen, Fakten, Grafiken (2017). Edited by BDEW Bundesverband der Energieund Wasserwirtschaft e.V. BDEW; 2017.

Benderitter Y, Cormy G. Possible approach to geothermal research and relative costs Small geothermal resources: a guide to development and utilization. New York: UNITAR; 1990. p. 59-69.

Bertani R, Leray B, Van Wees JD, Dumas P, Laenen B, Manzella A, Pellizzone A, Pinzuti V, van Baelen K, Garabetian T. Vision for deep geothermal. European Technology \& Innovation Platform on Deep Geothermal (ETIP-DG); 2018.

Bignall G, Kilgour GK, Milicich SD, Rae AJ, Ramirez E, Rosenberg MD. Geology of the Wairakei-Tauhara geothermal system, New Zealand. In: Proceedings of the world geothermal congress 2010, Bali, Indonesia, 25-29 April 2010.

Bine.info. BINE Informationsdienst Projektinfo; 2009. http://www.bine.info/fileadmin/content/Publikationen/Englische_ Infos/projekt_0409_engl_Internetx.pdf. Accessed Jan 2019.

Björnsson G, Bodvarsson G. A survey of geothermal reservoir properties. Geothermics. 1990;19(1):17-27. https://doi. org/10.1016/0375-6505(90)90063-H.

Bodvarsson G. Utilization of geothermal energy for heating purposes and combined schemes involving power generation, heating and/or by-products. In: Proceedings of the conference on new sources of energy, Rome, United Nations, NY, 1961, vol. 3, p. 429-36.

Bromley CJ, Mongillo M, Rybach L. Sustainable utilization strategies and promotion of beneficial environmental effectshaving your cake and eating it too. In: Proceedings of the 28th New Zealand geothermal workshop, Auckland, 2006

Campos Rodríguez CE, Escobar Palacio JC, Venturini OJ, Silva Lora EE, Cobas VM, Marques dos Santos D, Lofrano Dotto FR, Gialluca V. Exergetic and economic comparison of ORC and Kalina cycle for low temperature enhanced geothermal system in Brazil. Appl Therm Eng. 2013;52(1):109-19. https://doi.org/10.1016/j.applthermaleng.2012.11.012.

Chamorro CR, Mondéjar ME, Ramos R, Segovia JJ, Martín MC, Villamañán MA. World geothermal power production status - Energy, environmental and economic study of high enthalpy technologies. Energy. 2012;42(1):10-8. https://doi. org/10.1016/j.energy.2011.06.005.

Chen J, Jiang F. Designing multi-well layout for enhanced geothermal system to better exploit hot dry rock geothermal energy. Renew Energy. 2015;74:37-48. https://doi.org/10.1016/j.renene.2014.07.056. 
Dalmais E, Genter A, Trullenque G, Leoutre E, Leiss B, Wagner B, Minsta AC, Bär K, Rajsl I. MEET project: toward the spreading of EGS across Europe. In: Proceedings of the European geothermal congress, The Hague, The Netherlands, 11-14 June 2019.

EERE, U.S. Department of Energy's Office of Energy Efficiency and Renewable Energy. Geothermal electricity technology evaluation model (GETEM); 2016. https://www.energy.gov/eere/geothermal/geothermal-electricity-technology -evaluation-model. Accessed Nov 2020.

EEX. European Energy Exchange; 2019. https://www.eex.com/de/. Accessed Mar 2019.

EGEC, the European Geothermal Energy Council Geothermal. EGEC geothermal market report key findings 2019, 9th Edn; 2020.

EPA. Guide for conducting energy efficiency potential studies-a resource of the national action plan for energy efficiency. With assistance of Philip Mosenthal, Jeffrey Loiter. Edited by National Action Plan for Energy Efficiency; 2007.

Fetkovich MJ. Decline curve analysis using type curves, SPE-4629-PA. 1980; 32(06): 1065-1077.

Frank ED, Sullivan JL, Wang M. Life cycle analysis of geothermal power generation with supercritical carbon dioxide. Environ Res Lett. 2012. https://doi.org/10.1088/1748-9326/7/3/034030.

Fridleifsson IB. Geothermal energy for the benefit of the people. Renew Sustain Energy Rev. 2001;5(3):299-312. https:// doi.org/10.1016/S1364-0321(01)00002-8.

Friedleifsson IB, Bertani R, Lund JW, Rybach L. The possible role and contribution of geothermal energy to the mitigation of climate change. In: Hohmeyer O, Trittin T, editors. IPCC scoping meeting on renewable energy sources, Intergovernmental Panel on Climate Change (IPCC), Lübeck, Germany, 20-25 January 2008.

Garg SK, Combs J. Appropriate use of USGS volumetric "heat in place" Method and Monte Carlo calculations. In: Proceedings, thirty-fourth workshop on geothermal reservoir engineering. Stanford, California, February 1-3; 2010.

Gerard A, Kappelmeyer O. The Soultz-sous-Forets project. Geothermics. 1987;16(4):393-9. https://doi.org/10.1016/03756505(87)90018-6.

Gerber L, Maréchal F. Environomic optimal configurations of geothermal energy conversion systems-application to the future construction of Enhanced Geothermal Systems in Switzerland. Energy. 2012;45(1):908-23. https://doi. org/10.1016/j.energy.2012.06.068.

Grant AM, Garg SK. Recovery factor for enhanced geothermal systems. In: Proceedings, thirty-seventh workshop on geothermal reservoir engineering. California, January 30-February 1; 2012.

Gringarten AC. Reservoir lifetime and heat recovery factor in geothermal aquifers used for urban heating. PAGEOPH. 1978;117(1-2):297-308. https://doi.org/10.1007/BF00879755.

Gringarten AC, Sauty JP. Theoretical heat extraction from aquifers under uniformal flow. J Geophys Res. 1975;80(35):4956-62.

Haenel R, Rybach L, Stegena L. Fundamentals of geothermics. In: Handbook of terrestrial heat-flow density determination. Berlin: Springer; 1988.

Hähnlein S, Bayer P, Ferguson G, Blum P. Sustainability and policy for the thermal use of shallow geothermal energy. Energy Policy. 2013;59:914-25. https://doi.org/10.1016/j.enpol.2013.04.040.

Hasterok D, Webb J. On the radiogenic heat production of igneous rocks. Geosci Front. 2017:8(5):919-40. https://doi. org/10.1016/j.gsf.2017.03.006.

Hotelling H. The economics of exhaustible resources. J Polit Econ. 1931;39(2):137-75. https://doi.org/10.1086/254195.

Hutter G. Geothermal power generation in the world 2015-2020 update report. In: Proceedings of the world geothermal congress, Reykjavik, Iceland, 26 April-2 May 2020.

IRENA. Geothermal power: technology brief. Abu Dhabi: International Renewable Energy Agency; 2017.

Jelacic A, Fortuna R, LaSala R, Nathwani J, Nix G, Visser C, Green B, Renner J, Blankenship D, Kennedy M, Bruton C. An evaluation of enhanced geothermal systems technology—geothermal technologies program. Edited by U.S. Department of Energy, Washington D.C., USA; 2008.

Jiang F, Chen J, Huang W, Luo L. A three-dimensional transient model for EGS subsurface thermo-hydraulic process. Energy. 2014;72:300-10. https://doi.org/10.1016/j.energy.2014.05.038.

Knaut A, Madlener R, Rosen C, Vogt C. Effects of temperature uncertainty on the valuation of geothermal projects: a real options approach. FCN Working Paper No. 11/2012. Institute for Future Energy Consumer Needs and Behavior (FCN), RWTH Aachen University; 2012.

Kohl T, Baujard C, Manzella A, Schulte T, Karytsas C. ENGINE coordination action-best practice handbook for the development of unconventional geothermal resources with a focus on enhanced geothermal systems. Orleans; 2008.

Lukawski MZ, Anderson BJ, Augustine C, Capuano LE Jr, Beckers KF, Livesay B, Tester JW. Cost analysis of oil, gas, and geothermal well drilling. J Petrol Sci Eng. 2014;118:1-14.

Moeck IS. Catalog of geothermal play types based on geologic controls. Renew Sustain Energy Rev. 2014:37:867-82. https://doi.org/10.1016/j.rser.2014.05.032.

Mongillo MA, Bromley CJ, Rybach L. The IEA geothermal implementing agreement-international efforts to promote global sustainable geothermal development and help mitigate climate change. In: Proceedings of the world geothermal congress, Bali, Indonesia, 25-29 April 2010.

Mouchot J, Ravier G, Seibel O, Pratiwi A. Deep geothermal plants operation in Upper Rhine Graben: lessons learned. In: Proceedings of the European geothermal congress, The Hague, The Netherlands, 11-14 June 2019

Muffler LP. Assessment of geothermal resources of the United States. Reston: Geologic Div Geological Survey; 1979.

Muffler P, Cataldi R. Methods for regional assessment of geothermal resources. Geothermics. 1978;7(2-4):53-89. https:// doi.org/10.1016/0375-6505(78)90002-0.

Nathwani J, Mines G. Cost contributors to geothermal power generation. In: Proceedings of the world geothermal congress, Melbourne, Australia, 19-25 April 2015

O'Sullivan M, Yeh A, Mannington W. Renewability of geothermal resources. Geothermics. 2010;39(4):314-20. https://doi. org/10.1016/j.geothermics.2010.09.003.

Paschen H, Oertel D, Grünwald R. Möglichkeiten geothermischer Stromerzeugung in Deutschland. Edited by TAB Büro für Technikfolgen-Abschätzung beim Deutschen Bundestag, Berlin; 2003. 
Pawel I. The cost of storage - how to calculate the levelized cost of stored energy (LCOE) and applications to renewable energy generation. Energy Procedia. 2014;46:68-77. https://doi.org/10.1016/j.egypro.2014.01.159.

Perman R, Ma Y, McGilvray J, Common M. Natural resource and environmental economics. 3rd ed. New York: Pearson Education; 2003.

Proske A. Nutzung von Erdwärme mittels Erdwärmesonden - Anforderungen an das Speichergestein: TU Bergakademie Freiberg, Germany.

Rybach L. Geothermal energy — sustainability and the environment. Geothermics. 2003;32(4-6):463-70. https://doi. org/10.1016/\$0375-6505(03)00057-9.

Rybach L. The future of geothermal energy and its challenges. In: Proceedings of the world geothermal congress, Bali, Indonesia, 25-29 April 2010.

Rybach L, Mongillo M. Geothermal sustainability - a review with identified research needs. GRC Trans. 2006;30:1083-90.

Sanyal SK. Cost of geothermal power and factors that affect it. In: Proceedings, twenty-ninth workshop on geothermal reservoir engineering. Stanford, California, January 26-28. Richmond, California: GeothermEx, Inc; 2004.

Sanyal SK. Classification of geothermal systems-a possible scheme. In: Proceedings, thirtieth workshop on geothermal reservoir engineering, Stanford University, Stanford, California, 31 January-2 Februrary 2005.

Sanyal SK, Butler SJ. An analysis of power generation prospects from enhanced geothermal systems. In: Proceedings of the world geothermal congress, Antalya, Turkey, 24-29 April 2005.

Sanyal SK, Menzies AJ, Brown PJ, Enedy KL, Enedy S. A systematic approach to decline curve analysis for The Geysers steam field, California. Trans Geotherm Resour Council. 1989;13:415-21.

Sanyal SK, Butler SJ, Brown PJ, Goyal K, Box T. An investigation of productivity and pressure decline trends in geothermal steam reservoirs. In: Proceedings of the world geothermal congress, Kyushu-Tohoku, Japan, 28 May-10 June 2000.

Stefansson V. Success in geothermal development. Geothermics. 1992;21(5-6):823-34. https://doi.org/10.1016/03756505(92)90033-6.

Stefansson V. Geothermal reinjection experience. Geothermics. 1997;26(1):99-139. https://doi.org/10.1016/S0375 $-6505(96) 00035-1$.

Stefansson V. The renewability of geothermal energy. In: Proceedings of the world geothermal congress, Kyushu-Tohoku, Japan, 28 May-10 June 2000.

Stefansson V. Investment cost for geothermal power plants. Geothermics. 2002;31(2):263-72. https://doi.org/10.1016/ S0375-6505(01)00018-9.

Steingrímsson B, Axelsson G, Stefansson V. Reservoir management and sustainable use of geothermal energy; 2006.

Stober I, Bucher KE. Geothermie. 2nd ed. Berlin: Springer; 2014.

Tester JW, Anderson BJ, Batchelor AS, Blackwell DD, DiPippo R, Drake EM, Garnish J, Livesay B, Moore MC, Nichols K, Petty S, Toksöz MN, Veatch RW. The future of geothermal energy —impact of enhanced geothermal systems (EGS) on the United States in the 21st century. Cambridge: Massachusetts Institute of Technology; 2006.

Thorhallsson S, Sveinbjornsson BM. Geothermal drilling cost and drilling effectiveness. Short course on geothermal development and geothermal wells. Santana Tecla, El Salvador, March 11-17; 2012.

US Department of Energy. An evaluation of enhanced geothermal systems technology; 2009. https://doi. org/10.2172/1217838.

Vidal J, Genter A. Overview of naturally permeable fractures reservoirs in the central and southern Upper Rhine Graben: Insights from geothermal wells. Geothermics. 2018;74:57-73.

Walter R. Erdgeschichte - Die Geschichte der Kontinente, der Ozeane und des Lebens. 7. überarbeitete und verbesserte Auflage. Stuttgart: Schweizerbart; 2016.

White DE, Muffler LP, Truesdell AH. Vapor-dominated hydrothermal systems compared with hot-water systems. Econ Geol. 1971:66:75-97.

Williams CF. Thermal energy recovery from enhanced geothermal systems-evaluating the potential from deep, high-temperature resources. In: Proceedings, thirty-fifth workshop on geothermal reservoir engineering. Stanford University, Stanford, California, February 1-3, 2010. Menlo Park, CA 94025, USA: U.S. Geological Survey; 2010.

Zarrouk SJ, Moon H. Efficiency of geothermal power plants: a worldwide review. Geothermics. 2014;51:142-53. https:// doi.org/10.1016/j.geothermics.2013.11.001.

Zhang Y-J, Li Z-W, Guo L-L, Gao P, Jin X-P, XU T-F. Electricity generation from enhanced geothermal systems by oilfield produced water circulating through reservoir stimulated by staged fracturing technology for horizontal wells-a case study in Xujiaweizi area in Daqing Oilfield China. Energy. 2014;78:788-805. https://doi.org/10.1016/j.energ y.2014.10.073.

Ziagos J, Phillips BR, Boyd L, Jelacic A, Stillman G, Hass E. A technology roadmap for strategic development of enhanced geothermal systems. With assistance of John Ziagos, Benjamin R. Phillips, Lauren Boyd, Allan Jelacic, Greg Stillman, Eric Hass. In: Proceedings, thirty-eighth workshop on geothermal reservoir engineering, Stanford, California, February $11-13 ; 2013$.

Zweifel P, Praktiknjo A, Erdmann G. Energy economics - theory and applications. 1st ed. Berlin, New York: Springer; 2017.

\section{Publisher's Note}

Springer Nature remains neutral with regard to jurisdictional claims in published maps and institutional affiliations. 